Published in final edited form as:

Biochemistry. 2017 October 31; 56(43): 5771-5785. doi:10.1021/acs.biochem.7b00601.

\title{
Bacillus anthracis Prolyl 4-Hydroxylase Interacts with and Modifies Elongation Factor Tu
}

\author{
Nicholas J. Schnicker ${ }^{\dagger}$, Mortezaali Razzaghi ${ }^{\dagger}$, Sanjukta Guha Thakurta ${ }^{\ddagger}$, Srinivas \\ Chakravarthy§, and Mishtu Dey ${ }^{\star}, \dagger, I D$ \\ tDepartment of Chemistry, The University of lowa, lowa City, lowa 52242, United States \\ ¥Department of Cell Biology, Harvard Medical School, 240 Longwood Avenue, Boston, \\ Massachusetts 02115, United States
}

§Biophysics Collaborative Access Team, Argonne National Laboratory, Argonne, Illinois 60439, United States

\section{Abstract}

Prolyl hydroxylation is a very common post-translational modification and plays many roles in eukaryotes such as collagen stabilization, hypoxia sensing, and controlling protein transcription and translation. There is a growing body of evidence that suggests that prokaryotes contain prolyl 4-hydroxylases (P4Hs) homologous to the hypoxia-inducible factor (HIF) prolyl hydroxylase domain (PHD) enzymes that act on elongation factor $\mathrm{Tu}(\mathrm{EFTu})$ and are likely involved in the regulation of bacterial translation. Recent biochemical and structural studies with a PHD from Pseudomonas putida (PPHD) determined that it forms a complex with EFTu and hydroxylates a prolyl residue of EFTu. Moreover, while animal, plant, and viral P4Hs act on peptidyl proline, most prokaryotic P4Hs have been known to target free L-proline; the exceptions include PPHD and a $\mathrm{P} 4 \mathrm{H}$ from Bacillus anthracis $(\mathrm{BaP} 4 \mathrm{H})$ that modifies collagen-like proline-rich peptides. Here we use biophysical and mass spectrometric methods to demonstrate that $\mathrm{BaP} 4 \mathrm{H}$ recognizes fulllength BaEFTu and a BaEFTu 9-mer peptide for site-specific proline hydroxylation. Using sizeexclusion chromatography coupled small-angle X-ray scattering (SEC-SAXS) and binding studies, we determined that BaP4H forms a 1:1 heterodimeric complex with BaEFTu. The SECSAXS studies reveal dissociation of BaP4H dimeric subunits upon interaction with BaEFTu.

\footnotetext{
*Corresponding Author: Department of Chemistry, The University of Iowa, W285 Chemistry Building, Iowa City, IA 52242-1727. Telephone: 319-384-1319. Fax: 319-335-1270. mishtu-dey@uiowa.edu. 
While $\mathrm{BaP} 4 \mathrm{H}$ is unusual within bacteria in that it is structurally and functionally similar to the animal PHDs and collagen P4Hs, respectively, this work provides further evidence of its promiscuous substrate recognition. It is possible that the enzyme might have evolved to hydroxylate a universally conserved protein in prokaryotes, similar to the PHDs, and implies a functional role in $B$. anthracis.

\section{Graphical Abstract}

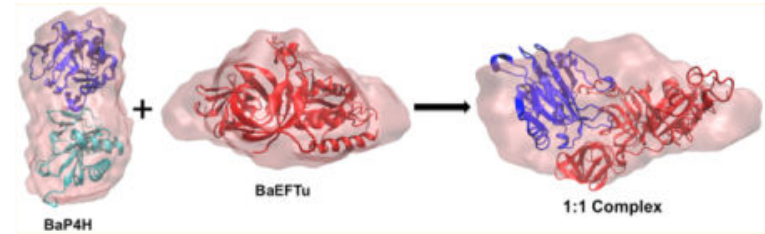

The post-translational hydroxylation of prolyl residues is catalyzed by prolyl 4-hydroxylases (P4Hs). These enzymes are involved in many essential biological processes in numerous different organisms. ${ }^{1-6} \mathrm{P} 4 \mathrm{Hs}$ belong to the group of $\mathrm{Fe}(\mathrm{II}) / a$-ketoglutarate $(a \mathrm{KG})$ dependent dioxygenases (FAKGDs) that require $\mathrm{Fe}(\mathrm{II}), a \mathrm{KG}$, and $\mathrm{O}_{2}$ for catalysis. ${ }^{6-10}$ FAKGDs contain a highly conserved double-stranded $\beta$-helix domain comprising a 2 His-1carboxylate (Asp/Glu) catalytic triad that coordinates to the active site $\mathrm{Fe}(\mathrm{II}){ }^{7,11,12} \mathrm{In}$ reactions catalyzed by FAKGDs, oxidation of a substrate is coupled to the decarboxylation of the co-substrate $a \mathrm{KG}$, yielding succinate and carbon dioxide. P4Hs accomplish $\mathrm{C}-\mathrm{H}$ bond activation in substrates containing prolyl residues through a highly reactive $\mathrm{Fe}(\mathrm{IV})$ intermediate that abstracts a hydrogen atom. These enzymes activate dioxygen and incorporate one atom from $\mathrm{O}_{2}$ into the substrate, generating 4-hydroxyproline (Hyp), whereas the second atom is consumed in the formation of succinate (Figure 1). ${ }^{10,12,13}$

The biological consequence of prolyl hydroxylation is varied; however, the most-studied $\mathrm{P} 4 \mathrm{Hs}$ in humans and other animals are known to be involved in the cellular response to hypoxia and in collagen biosynthesis. The collagen P4Hs hydroxylate prolyl residues at the $\mathrm{Y}$ position of $(\mathrm{X}-\mathrm{Y}-\mathrm{G})_{n}$ repeats in collagens and proteins with a collagen-like sequence (where $n$ denotes the number of repeated sequences). The $\mathrm{X}$ position can be occupied by various residues but is frequently another proline in humans. ${ }^{4,5,14,15}$ The formation of Hyp in the Y position of collagen is critical to the stability of collagen triple helices. ${ }^{16,17}$ On the other hand, the P4Hs that act as cellular oxygen sensors include the prolyl hydroxylase domain (PHD) enzymes responsible for regulating hypoxia-inducible transcription factor $1 a$ (HIF-1a). The PHDs hydroxylate prolyl residues in the LXXLAP motif of HIF-1 $a$ under normoxic conditions, targeting it for proteasomal degradation (Figure 1). ${ }^{2,18}$ A PHD isoform, PHD2 has been shown to modulate the activity of eukaryotic elongation factor 2 (eEF2) that contains HIF-like sequence motifs consisting of a proline preceded by two leucines (LXLXP) and controls protein translation. ${ }^{19}$ While eEF2 interacts with PHD2, it has not been determined whether PHD2 regulates eEF2 function by its prolyl hydroxylation activity. 19

As in humans, the P4Hs in green algae and viruses recognize various peptidyl prolyl residues in diverse substrates and are involved in regulating different functions of the host 
organism. ${ }^{20-22}$ In contrast, most prokaryotic $\mathrm{P} 4 \mathrm{Hs}$ were known to use free L-proline as a substrate to produce Hyp. ${ }^{4}$ The homodimeric $\mathrm{P} 4 \mathrm{H}$ from Bacillus anthracis $(\mathrm{BaP} 4 \mathrm{H})$ is unusual within bacteria and targets collagen-like proline-rich peptides. ${ }^{23,24} \mathrm{~A}$ ConSurf analysis of $\mathrm{BaP} 4 \mathrm{H}$ with various $\mathrm{P} 4 \mathrm{Hs}$ shows a high degree of conservation of residues, despite their diverse biological origins, ${ }^{4,25}$ including common substrate recognition motifs (Figure $\mathrm{S} 1$ ). We have previously demonstrated that $\mathrm{BaP} 4 \mathrm{H}$ asymmetrically hydroxylates unique peptidyl proline sites in collagen-like (P-P-G) $)_{5,10}$ peptides $^{23}$ and is unique among bacterial P4Hs in that it is structurally and functionally related to the animal PHDs and human collagen $\mathrm{P} 4 \mathrm{H}$, respectively. On the basis of a genomic analysis of collagen structural motifs (CSMs) in bacteria, it has been predicted that the collagen repeats found in animals are relatively rare among prokaryotes and bacterial CSMs are dominated by threonine-rich (G-P-T) repeats. ${ }^{15}$ Furthermore, the proteome of $B$. anthracis contains proteins with collagen-like motifs of $(\mathrm{G}-\mathrm{P}-\mathrm{T})_{n}$ repeats.

Previous liquid chromatography-mass spectrometry (LC-MS/MS) analysis of the proteome of Shewanella oneidensis MR-1 revealed that translational elongation factor Tu (TufB) is hydroxylated at Pro 54 by an uncharacterized P4H. ${ }^{26}$ Likewise, a PHD from Pseudomonas putida (PPHD) has been shown to hydroxylate a proline residue (Pro 54) located on the switch I loop region of elongation factor Tu (EFTu), suggesting its potential involvement in bacterial translation. ${ }^{27} \mathrm{~A}$ crystal structure of the PPHD-EFTu complex shows conformational changes upon substrate binding and various substrate recognition interactions that are conserved among other P4Hs. ${ }^{25,27}$ The sequences of neither EFTu nor TufB contain the canonical leucine-proline motifs or proline-rich repeats usually targeted by PHDs or P4Hs, respectively. Examination of the proteome of $B$. anthracis reveals the sequence of the highly conserved EFTu (BaEFTu) is $\sim 70 \%$ identical to those of the P. putida and $S$. oneidensis homologues.

In this study, we examine if $\mathrm{BaP} 4 \mathrm{H}$ targets BaEFTu for proline hydroxylation and find that it indeed modifies Pro 54 of BaEFTu in addition to six other minor hydroxylation sites. While BaP4H interacts with the BaEFTu-9 peptide with a $K_{\mathrm{d}}$ of $\sim 77 \mathrm{nM}$, the interaction between $\mathrm{BaP} 4 \mathrm{H}$ and full-length BaEFTu is relatively weak $\left(K_{\mathrm{d}}\right.$ of $\left.\sim 12 \mu \mathrm{M}\right)$, which is further attenuated in the presence of $200 \mathrm{mM} \mathrm{NaCl}$. Furthermore, we determine the stoichiometry of binding and find that the interaction of the two proteins induces substantial structural reorganization, leading to subunit dissociation of the $\mathrm{BaP} 4 \mathrm{H}$ dimer, thereby forming a 1:1 complex in solution.

\section{MATERIALS AND METHODS}

\section{Materials}

All buffers, ingredients of media, and other reagents were acquired from Sigma-Aldrich (St. Louis, MO) and, unless otherwise stated, were of the highest purity available. Solutions were prepared using Nanopure deionized water. $\mathrm{N}_{2}(99.98 \%$ ) was obtained from Praxair (Cedar Rapids, IA). The BaEFTu-9-mer peptide was synthesized by GenScript (Piscataway, NJ) with the sequence DAAPEERER. This peptide was designed on the basis of a sequence alignment of BaEFTu with other EFTus (not shown) and contains the proline that was shown to undergo hydroxylation in P. putida EFTu. 


\section{Protein Expression and Purification}

Apo-BaP4H was expressed and purified as reported previously. ${ }^{28,29}$ The gene encoding EFTu from B. anthracis in the pMCSG7 vector was a generous gift from K. Kwon and S. Grimshaw at the J. Craig Venter Institute. The BaEFTu plasmid containing a six-His tag was transformed into Escherichia coli Rosetta 2(DE3)pLysS cells (Life Technologies, Grand Island, NY). Cell cultures were grown in $2 \times Y T$ medium to an $\mathrm{OD}_{600}$ of 0.6 at $37^{\circ} \mathrm{C}$ before being induced with $1 \mathrm{mM}$ isopropyl $\beta$-D-1-thiogalactopyranoside. Cells were grown for $6 \mathrm{~h}$ at $25{ }^{\circ} \mathrm{C}$, harvested by centrifugation at $4000 \mathrm{rpm}$ for $30 \mathrm{~min}$ at $4{ }^{\circ} \mathrm{C}$, and stored at $-80{ }^{\circ} \mathrm{C}$. Frozen cell paste $(8 \mathrm{~g})$ was resuspended in lysis buffer [50 mM HEPES (pH 7.5), $500 \mathrm{mM}$ $\mathrm{NaCl}, 20 \mathrm{mM}$ imidazole, and $0.5 \mathrm{mM}$ tris(3-hydroxypropyl)phosphine], with $1 \mathrm{mM}$ phenylmethanesulfonyl fluoride, lysozyme, DNase, and RNase added, and sonicated on ice followed by centrifugation at $20000 \mathrm{rpm}$ for $30 \mathrm{~min}$ at $4{ }^{\circ} \mathrm{C}$. The supernatant was loaded onto a $5 \mathrm{~mL}$ Ni(II)-nitrilotriacetic acid agarose column (MCLAB, San Francisco, CA) preequilibrated in lysis buffer. The column was washed with $50 \mathrm{~mL}$ of lysis buffer before protein fractions were collected in elution buffer [50 mM HEPES (pH 7.5), $500 \mathrm{mM} \mathrm{NaCl}$, $250 \mathrm{mM}$ imidazole, and $0.5 \mathrm{mM}$ tris(3-hydroxypropyl)-phosphine]. Fractions were analyzed by sodium dodecyl sulfate-polyacrylamide gel electrophoresis (SDS-PAGE), pooled, concentrated using an Amicon Ultra 5000 molecular weight cutoff membrane (Millipore, Billerica, MA), and loaded onto a Superdex 200 16/60 column (120 mL, GE Healthcare) pre-equilibrated in $50 \mathrm{mM}$ HEPES (pH 7.5), $200 \mathrm{mM} \mathrm{NaCl}, 10 \mathrm{mM} \mathrm{MgCl}_{2}$, and $1 \mu \mathrm{M}$ guanosine diphosphate (GDP). BaEFTu fractions $(2.5 \mathrm{~mL})$ that were $>99 \%$ pure on the basis of SDS-PAGE were combined and concentrated to $8.5 \mathrm{mg} / \mathrm{mL}$; aliquots were stored at $-80{ }^{\circ} \mathrm{C}$ until they were used.

\section{Fluorescence Binding Titrations}

Fluorescence spectra were recorded at room temperature as described previously with slight modifications. ${ }^{23,28}$ The intrinsic tryptophan fluorescence was used in titration experiments to determine the dissociation constant of binding of BaEFTu-9 to BaP4H. The wavelength used for excitation was $295 \mathrm{~nm}$, and the emission was monitored from 310 to $400 \mathrm{~nm}$ using an excitation slit width of $5 \mathrm{~nm}$ and an emission slit width of $10 \mathrm{~nm}$. The signal intensity was recorded at the maximum of $329 \mathrm{~nm}$. Titration experiments were performed using 0.25 $\mu \mathrm{M}$ apo-BaP4H in $50 \mathrm{mM}$ Tris $\mathrm{pH}$ (7.4) and $30 \mathrm{mM} \mathrm{NaCl}$ containing $5 \mu \mathrm{M}\left(\mathrm{NH}_{4}\right)_{2} \mathrm{Fe}(\mathrm{II})$ $\left(\mathrm{SO}_{4}\right)_{2}$ and $100 \mu \mathrm{M} a \mathrm{KG}$. All titrations were performed anaerobically, to prevent turnover in the presence of $\mathrm{O}_{2}$, using solutions that were prepared in a glovebox. In a typical titration, a degassed solution $(3 \mathrm{~mL})$ of protein and cofactors was sealed in a screw top quartz cuvette with a septum. Anaerobic solutions of BaEFTu-9 were added in aliquots via syringe to the quartz cuvette. The data were fit with Sigma Plot 12.0 (Systat Software Inc., Point Richmond, CA) using eq 1 as described previously 23,30

$$
f=f_{\mathrm{o}}+\left(f_{\mathrm{m}}-f_{\mathrm{o}}\right) \frac{n P+x+K_{d}-\sqrt[2]{\left(n P+x+K_{d}\right)^{2}-4 n P x}}{2 n P}
$$

where $f$ is the fluorescence signal resulting from binding of the peptide, $f_{\mathrm{o}}$ is the signal from a protein solution in the absence of any peptide, fm corresponds to the maximal quenched 
fluorescence intensity when the peptide is bound, $K_{\mathrm{d}}$ is the dissociation constant, $P$ and $x$ are the total protein and ligand concentrations, respectively, and $n$ is the number of binding sites.

\section{Hydroxylation Product Identification by LC-MS}

Enzymatic assays to verify BaEFTu-9 peptide prolyl hydroxylation were performed inside a glovebox using an oxygen-saturated buffer containing $100 \mathrm{mM}$ Tris (pH 7.4) as described previously. ${ }^{23}$ A solution of apo-BaP4H $(10$ or $50 \mu \mathrm{M})$ was preincubated anaerobically with an equimolar concentration of $\left(\mathrm{NH}_{4}\right)_{2} \mathrm{Fe}(\mathrm{II})\left(\mathrm{SO}_{4}\right)_{2}$ for $30 \mathrm{~min}$. A reaction mixture containing ascorbate (10 or $50 \mu \mathrm{M}), 500 \mu \mathrm{M} a \mathrm{KG}$, and $100 \mu \mathrm{M}$ BaEFTu-9 was anaerobically prepared at $20^{\circ} \mathrm{C}$. The reactions were initiated by the addition of the preincubated solution of $\mathrm{Fe}(\mathrm{II})-\mathrm{BaP} 4 \mathrm{H}$ and allowed to react for $45 \mathrm{~min}$ at $20^{\circ} \mathrm{C}$. The reactions were quenched in $0.5 \%$ trifluoroacetic acid (TFA) and vacuum concentrated (SpeedVac Concentrator, Savant, SPD131DDA). The dried powder containing the product was collected and stored at $4{ }^{\circ} \mathrm{C}$ prior to analysis. Assays for examining the hydroxylation of full-length BaEFTu were performed in the same manner as they were for BaEFTu-9 using $50 \mu \mathrm{M} \mathrm{BaP} 4 \mathrm{H}, 50 \mu \mathrm{M}$ Fe(II), $50 \mu \mathrm{M}$ ascorbate, $500 \mu \mathrm{M} a \mathrm{KG}$, and $100 \mu \mathrm{M}$ full-length $\mathrm{BaEFTu}$. Reactions were quenched by freezing and mixtures stored prior to LC-MS analysis.

All LC-MS/MS data were collected on an Orbitrap Fusion mass spectrometer (Thermo Fisher Scientific) equipped with an Easy-nLC 1000 instrument for sample handling and peptide separations. A protein fraction isolated from $B$. anthracis was separated using onedimensional gel electrophoresis prior to MS analysis. Approximately $5 \mu \mathrm{g}$ of total protein sample and $1 \mu \mathrm{g}$ of BaEFTu control were run on NuPAGE 4 to $12 \%$ Bis-Tris precast gels in MES buffer for 30 min according to the manufacturer's procedure, stained with Coomassie blue, and thoroughly rinsed to remove unbound dye. A band of approximately $40-60 \mathrm{kDa}$ was excised, destained, reduced, and alkylated prior to in-gel digestion (overnight at $37{ }^{\circ} \mathrm{C}$ ) with $5 \mathrm{mg} / \mathrm{mL}$ trypsin. Following digestion, supernatants were collected, desalted by stage tipping, and dried down in a vacuum centrifuge. The synthetic peptide (BaEFTu-9) and tryptic BaEFTu peptides were resuspended in $10 \mathrm{~mL}$ of $5 \%$ formic acid and $5 \%$ acetonitrile before being analyzed by LC-MS/MS. Peptide solutions were loaded onto a $100 \mu \mathrm{m}$ inner diameter fused silica microcapillary with a needle tip pulled to an internal diameter of $<5$ $\mu \mathrm{m}$. The column was packed in house to a length of $15 \mathrm{~cm}$ with a $\mathrm{C}_{18}$ reverse phase resin (120 Å pore size, $5.0 \mu \mathrm{m}$ particle size, GP-C 18 , SePax Technologies). The synthetic peptide was separated using a 20 min linear gradient (a 45 min gradient was used for BaEFTu tryptic peptides) from 0 to $30 \%$ buffer B (100\% acetonitrile and $0.125 \%$ formic acid) equilibrated with buffer $\mathrm{A}$ ( $3 \%$ acetonitrile and $0.125 \%$ formic acid).

The Orbitrap Fusion mass spectrometer was operated in data-dependent positive ion mode using the top speed strategy. In brief, the Orbitrap Fusion method for the synthetic peptide began with an $\mathrm{MS}^{1}$ spectrum (Orbitrap analysis, resolution of 120000), an $\mathrm{m} / \mathrm{z} 150-1200$ scan range, an automated gain control (AGC) target of $5 \times 10^{5}$, a maximum injection time of $100 \mathrm{~ms}$, and a dynamic exclusion of $5 \mathrm{~s}$. MS ${ }^{2}$ fragment ions were analyzed in the Orbitrap, at a resolution of 15000. "Top speed" ( $2 \mathrm{~s})$ was selected for $\mathrm{MS}^{2}$ analysis, which consisted of higher-energy collisional dissociation fragmentation, a quadrupole isolation of 2.0 Da, an 
AGC target of $1 \times 10^{5}$, a collision energy of $25 \%$, and a maximum injection time of $250 \mathrm{~ms}$. The Fusion method for the synthetic peptide began with an $\mathrm{MS}^{1}$ spectrum (Orbitrap analysis, resolution of 120000), an $\mathrm{m} / \mathrm{z} 300-2000$ scan range, an AGC target of $5 \times 10^{5}$, a maximum injection time of $100 \mathrm{~ms}$, and a dynamic exclusion of $30 \mathrm{~s}$. $\mathrm{MS}^{2}$ fragment ions were analyzed in the Orbitrap, at a resolution of 15000. "Top speed" ( $2 \mathrm{~s})$ was selected for $\mathrm{MS}^{2}$ analysis, which consisted of collision-induced dissociation fragmentation, a quadrupole isolation of $0.7 \mathrm{Da}$, an AGC target of $1 \times 10^{5}$, a collision energy of $25 \%$, and a maximum injection time of $100 \mathrm{~ms}$.

A suite of in-house software tools was used for .RAW file processing and controlling peptide false discovery rates. MS/MS spectra were searched against either custom databases containing the BaEFTu-9 sequence (synthetic peptide) or a UniProt database of $B$. anthracis for full-length BaEFTu along with 100 common contaminants with both the forward and reverse sequences. Database search criteria are as follows: tryptic with two missed cleavages, a precursor mass tolerance of $1 \mathrm{Da}$, a fragment ion mass tolerance of $0.03 \mathrm{Da}$, and variable hydroxylation of proline $(15.99491 \mathrm{Da})$. Peptides were filtered to a $1 \%$ false discovery rate using linear discriminate analysis. ${ }^{31}$ We used a modified version of the Ascore algorithm (ModScore) to quantify the confidence with which each hydroxylation site could be assigned to a particular residue. Hydroxylation sites with ModScore threshold values of $>19(p<0.01)$ were considered confidently localized to a particular residue. ${ }^{31}$ Peptides with one or more hydroxylation site(s) localized to $>99 \%$ confidence are listed in Table 1.

\section{Gel-Filtration Analysis of Complex Formation}

Solutions of BaP4H (25 kDa), BaEFTu (43 kDa), and a 1:1 BaP4H/BaEFTu mixture were injected onto a Superdex 200 10/300 GL gel-filtration column (24 mL, GE Healthcare) with a $0.2 \mathrm{~mL}$ loop at $0.75 \mathrm{~mL} / \mathrm{min}$ using an AKTA Pure FPLC system (GE Healthcare). The column was calibrated in the absence and presence of $200 \mathrm{mM} \mathrm{NaCl}$ with gel-filtration molecular weight (MW) standards (Bio-Rad) containing thyroglobulin (670 kDa, bovine), $\gamma$ globulin (158 kDa, bovine), ovalbumin (44 kDa, chicken), myoglobin (17 kDa, horse), and vitamin $\mathrm{B}_{12}(1.35 \mathrm{kDa})$ (Figure $\left.\mathrm{S} 2\right)$. The eluting protein and the complex were detected by monitoring the ultraviolet (UV) absorbance at $280 \mathrm{~nm}$. To analyze the formation of the complex between BaP4H and BaEFTu, $200 \mu \mathrm{L}$ solutions each of BaP4H $(2 \mathrm{mg} / \mathrm{mL})$ and BaEFTu $(4 \mathrm{mg} / \mathrm{mL}$ ) were mixed in 1:1 molar ratio (to a final concentration of $80 \mu \mathrm{M}$ ) at $4{ }^{\circ} \mathrm{C}$ in $50 \mathrm{mM}$ HEPES (pH 7.5), $10 \mathrm{mM} \mathrm{MgCl}_{2}$, and $1 \mu \mathrm{M} \mathrm{GDP}$ (complex buffer) and loaded onto the column pre-equilibrated in the complex buffer. In a separate experiment, protein solutions were further injected onto the same column in the complex buffer containing $200 \mathrm{mM} \mathrm{NaCl}$ to observe the effect of $\mathrm{NaCl}$ on complex formation. The eluting protein complex was compared to injections of $200 \mu \mathrm{L}$ solutions of either $2 \mathrm{mg} / \mathrm{mL}$ (for $\mathrm{BaP} 4 \mathrm{H}$ ) or $4 \mathrm{mg} / \mathrm{mL}$ (for BaEFTu) onto the same column in $50 \mathrm{mM}$ HEPES (pH 7.5), 200 $\mathrm{mM} \mathrm{NaCl}, 10 \mathrm{mM} \mathrm{MgCl}_{2}$, and $1 \mu \mathrm{M}$ GDP. Fractions $(0.5 \mathrm{~mL})$ were collected with a AKTA F9-R fraction collector and analyzed by SDS-PAGE for visual inspection of the BaP4HBaEFTu complex. 


\section{Isothermal Titration Calorimetry (ITC)}

The binding of $\mathrm{BaP} 4 \mathrm{H}$ with full-length BaEFTu was measured using an iTC200 microcalorimeter (Microcal, Inc., Northampton, MA), equipped with a temperaturecontrolled cell ( $200 \mu \mathrm{L}$ cell volume), and a $40 \mu \mathrm{L}$ syringe. Prior to the titrations, stock solutions of the proteins were passed through an SEC column (Superdex 200 10/300 GL) and protein concentrations were measured using a Bradford assay. Titration experiments were performed at $5{ }^{\circ} \mathrm{C}$, with $\mathrm{BaP} 4 \mathrm{H}$ added to BaEFTu in the sample cell. Briefly, $1.12 \mathrm{mM}$ $\mathrm{BaP} 4 \mathrm{H}$ was placed into a syringe and immersed in the cell containing $80 \mu \mathrm{M}$ BaEFTu. Approximately 20 aliquots ( $2 \mu \mathrm{L}$ each) of $\mathrm{BaP} 4 \mathrm{H}$ at $180 \mathrm{~s}$ intervals were injected into the sample cell containing $200 \mu \mathrm{L}$ of either BaEFTu or buffer alone [50 mM HEPES (pH 7.5), $10 \mathrm{mM} \mathrm{MgCl}_{2}$, and $1 \mu \mathrm{M} \mathrm{GDP}$, and $0.1 \mathrm{mM} \beta$-mercaptoethanol]. The heat of dilution obtained by injecting $\mathrm{BaP} 4 \mathrm{H}$ into the buffer was subtracted from the heats of binding. The titration experiment was performed in triplicate, and the data were analyzed with Microcal ORIGIN 7.0 software using a single-site binding model to determine the equilibrium association constant, $K_{\mathrm{A}}\left(=1 / K_{\mathrm{d}}\right)$, and the binding enthalpy, $\Delta H^{\circ}$. The Gibbs free energy of binding, $\Delta G^{\circ}$, and the entropic contribution to the binding free energy, $-T \Delta S^{\circ}$, were calculated using eq 2 .

$$
\Delta G^{\circ}=\Delta H^{\circ}-T \Delta S^{\circ}
$$

\section{Size-Exclusion Chromatography (SEC) Coupled Small-Angle X-ray Scattering (SAXS) Data Collection and Analysis}

SEC-SAXS experiments were performed at BioCAT (beamline 18-ID-D at the Advanced Photon Source, Argonne National Laboratory, Argonne, IL). The SEC-SAXS setup included a camera with a focused $12 \mathrm{keV}(1.03 \AA) \mathrm{X}$-ray beam, a $1.5 \mathrm{~mm}$ quartz capillary sample cell, an $\sim 3.5 \mathrm{~m}$ long flight tube between samples, and a Pilatus $31 \mathrm{M}$ detector (Dectris). ${ }^{32}$ The $q$ range sampled was $\sim 0.004-0.4 \AA^{-1}$. To ensure sample monodispersity, an in-line SEC setup was used, which included an AKTA-pure FPLC unit and a Superdex-200 Increase 10/300 GL column (GE Healthcare Life Sciences). The gel-filtration column was equilibrated with $50 \mathrm{mM}$ HEPES (pH 7.5), $10 \mathrm{mM} \mathrm{MgCl}$, and $1 \mu \mathrm{M}$ GDP (complex buffer). A $500 \mu \mathrm{L}$ solution of BaP4H or BaEFTu at $10 \mathrm{mg} / \mathrm{mL}$ was loaded onto the column. BaP4H and $\mathrm{BaEFTu}$ were added in the complex buffer to final concentrations of $80 \mu \mathrm{M}$ each for the complex. The elution trajectory after the UV monitor was redirected to the SAXS sample flow cell. Exposures ( $1 \mathrm{~s}$ ) were collected every $3 \mathrm{~s}$ during the gel-filtration chromatography run. Appropriate exposures flanking the elution peak were averaged and used as the buffer curve for each run, and the exposures during elution (coincident with the UV peak on the chromatogram) were treated as protein + buffer curves. Data were corrected for background scattering by subtracting the buffer curve from protein + buffer curves.

Preliminary data analyses were performed using PRIMUS ${ }^{33}$ and ATSAS packages,${ }^{34}$ which produced the protein scattering profile, $I(q)$, as a function of momentum transfer $q$, where $q$ $=4 \pi / \lambda \sin \theta$ (where $2 \theta$ is the scattering angle and $\lambda$ is the $X$-ray wavelength). Guinier plots were made in Sigma Plot 12.0 (Systat Software Inc.) using the equation described by 
Putnam et al., ${ }^{35}$ and the radius of gyration $\left(R_{\mathrm{g}}\right)$ was calculated by fitting the Guinier plot to the Guinier equation. ${ }^{35}$ The pair distribution function, $P(r)$, was calculated using GNOM, ${ }^{34}$ and ab initio shape reconstructions were performed using DAMMIF. ${ }^{36}$ DAMMIF was performed 10-20 independent times, and the results were averaged using DAMAVER to generate the final volumetric bead model rendered using VMD. ${ }^{37}$ Rigid body docking was performed using SUPCOMB ${ }^{38}$ with appropriate crystal or homology model structures into the envelope generated by DAMMIF. Shape reconstruction statistics are listed in Supporting Table 1.

\section{Crystallization of the Co(II)-BaP4H Closed Conformation and Structural Determination}

A solution of $10 \mathrm{mg} / \mathrm{mL}$ apo-BaP4H, $1 \mathrm{mM} \mathrm{CoCl} 2,1 \mathrm{mM} a \mathrm{KG}$, and $1 \mathrm{mM} \mathrm{BaEFTu}-9$ peptide was incubated on ice for 30 min before setting crystal drops. Crystals were obtained using hanging-drop vapor diffusion at $20^{\circ} \mathrm{C}$ from the MPD screen (Qiagen) by mixing $1 \mu \mathrm{L}$ of the protein solution described above with $1 \mu \mathrm{L}$ of the reservoir solution. Initial crystals appeared after 4 days in $0.1 \mathrm{M}$ imidazole (pH 8.0), 5\% PEG 4000, and 15\% MPD and were optimized by varying the $\mathrm{pH}$ and precipitant concentration. Crystals were rod-shaped and grew to dimensions of $\sim 200 \mu \mathrm{m} \times 40 \mu \mathrm{m} \times 40 \mu \mathrm{m}$. Data were collected on crystals grown from $0.1 \mathrm{M}$ imidazole ( $\mathrm{pH} 8.0$ ), $11 \%$ PEG 4000, and 30\% MPD. Crystals were taken directly from the precipitant condition and submerged in liquid nitrogen.

The BaP4H data set was collected at $100 \mathrm{~K}$ at the Advanced Light Source, beamline 4.2.2. Data collection parameters were as follows: $0.2^{\circ}$ oscillation, $0.4 \mathrm{~s}$ exposure time, and 250 $\mathrm{mm}$ detector distance. The data were indexed, integrated, and scaled using $\mathrm{XDS}^{39}$ and merged using AIMLESS. ${ }^{40}$ Data collection and refinement statistics are summarized in Table 2. Molecular replacement for Co(II)-BaP4H was performed with PHASER ${ }^{41}$ using 5IAV as a starting model, which resulted in a translation factor $Z$ score of 93.7 and loglikelihood gain of 11649. The Matthews coefficient and estimated solvent content were 2.2 $\AA^{3} / \mathrm{Da}$ and $44 \%$, respectively. Refinement was performed using phenix.refine from the PHENIX software package. ${ }^{42}$ Metal-ligand bond lengths and angles were generated using phenix.metal_coordination. Refinement was performed using simulated annealing, energy minimization, real space, and $B$ factor refinement parameters, and model building was performed in Coot. ${ }^{43}$ Verification of ligand placement was based on a simulated annealing omit map generated by omitting the ligand. Water molecules were added to obvious density in later rounds of refinement. Previous structures of $\mathrm{BaP} 4 \mathrm{H}$ typically contained a disordered $\mathrm{N}$-terminus and a flexible loop region that varied slightly for each chain. The disordered residues that were not modeled for each chain are as follows: chain A, 1-9; chain B, 1-10; chain C, 1-10 and 67-71; chain D, 1-10 and 68-74. In chains A, C, and D, density for TFA and imidazole was observed in the space typically occupied by $a \mathrm{KG}$ as in chain $\mathrm{B}$. The source of TFA was the synthesized peptide. Chains A and B form a dimer as do chains C and D. Chain A from the symmetry molecule (residues 60-69) packs against the active site of chain B. The structure was refined to $R_{\text {work }}$ and $R_{\text {free }}$ values of 16.1 and 20.9, respectively, and was validated in the wwPDB Validation server. All structural figures were made using PyMOL. ${ }^{44}$ The software was curated by SBGrid. ${ }^{45}$ 


\section{Peptide Docking}

The BaP4H structure (PDB entry 5V7Y, chain B) was superimposed with chain A (PPHD) of the PPHD-EFTu complex (PDB entry 4IW3) in Coot to create a model for docking. The residues of EFTu in chain $\mathrm{B}$ of the complex were mutated to the corresponding residues of BaEFTu. Docking was performed using the BaEFTu-9 peptide (DAAPEERER). The peptide coordinates were merged with the $\mathrm{BaP} 4 \mathrm{H}$ structure and submitted to the ZDOCK server for rigid body docking. ${ }^{46}$ The most reasonable peptide conformation from ZDOCK was optimized using FlexPepDock for flexible peptide docking as previously described. ${ }^{23,47,48}$

\section{RESULTS}

\section{BaP4H Binds and Hydroxylates BaEFTu-9-mer Peptide}

While we have shown in previous studies that $\mathrm{BaP} 4 \mathrm{H}$ hydroxylates human collagen-like peptides containing (P-P-G) 5,10 repeats; nonetheless, the same collagen regions found in animals are rarely observed in prokaryotes. ${ }^{15}$ To examine if $\mathrm{BaP} 4 \mathrm{H}$ recognizes BaEFTu as a substrate, we initially conducted binding and hydroxylation studies using a synthetic BaEFTu-9 peptide. The peptide binding affinity of $\mathrm{BaP} 4 \mathrm{H}$ was measured by monitoring the decrease in intrinsic tryptophan fluorescence, and the dissociation constant $\left(K_{\mathrm{d}}\right)$ was determined to be $77 \pm 3 \mathrm{nM}$ (Figure 2A). BaP4H exhibits 5-10-fold higher affinity for BaEFTu-9 than for collagen-like $(\mathrm{P}-\mathrm{P}-\mathrm{G})_{5}\left(K_{\mathrm{d}}=300 \pm 20 \mathrm{nM}\right)$ and $(\mathrm{P}-\mathrm{P}-\mathrm{G})_{10}\left(K_{\mathrm{d}}=740\right.$ $\pm 110 \mathrm{nM}$ ) peptides. ${ }^{23}$ Nonlinear regression analysis revealed a stoichiometry of $0.96 \mathrm{~mol}$ of BaEFTu-9 per BaP4H monomer, indicating a 1:1 molar binding ratio (not shown).

To determine if $\mathrm{BaP} 4 \mathrm{H}$ hydroxylates the proline residue in the $\mathrm{BaEFTu}-9$ peptide, hydroxylation assays were performed using two different protein concentrations (see the Materials and Methods), and the isolated products were analyzed by LC-MS/MS. The extracted ion chromatogram (XIC) showed that hydroxylated BaEFTu-9 eluted as a single peak at 5.5 min (Figure 2B), whereas in the absence of BaP4H, the BaEFTu-9 peptide eluted as a split peak between 6 and $6.5 \mathrm{~min}$, presumably because of cis-trans isomerization in the unhydroxylated form (Figure 2B). The hydroxylated BaEFTu-9 product appears at $\mathrm{m} / \mathrm{z}$ 363.5038 and corresponds to a triply charged species (Figure 2C and Table 1). The unhydroxylated BaEFTu-9 peptide was observed at $\mathrm{m} / \mathrm{z} 358.1718$. Hydroxylation of BaEFTu-9 results in an $\mathrm{m} / \mathrm{z}$ change of 5.3320 for the triply charged ion, which is equivalent to a $15.996 \mathrm{Da}$ increase in the peptide mass corresponding to incorporation of a single oxygen atom (Figure $2 \mathrm{C}$ ).

\section{BaP4H Site-Specifically Hydroxylates Full-Length BaEFTu and Forms a Stable Binary Complex}

To determine if $\mathrm{BaP} 4 \mathrm{H}$ hydroxylates the same proline (Pro 54) in full-length BaEFTu that corresponds to the proline in the BaEFTu-9 peptide, enzymatic assays were performed with full-length BaEFTu. Following in-gel tryptic digestion of BaEFTu that was incubated with $\mathrm{BaP} 4 \mathrm{H}$, the hydroxylation products were analyzed by LC-MS/MS (Figure 3A,B). The XIC and MS1 spectra confirm the hydroxylation of Pro 54, which is one of seven unique prolyl hydroxylation sites identified for BaEFTu upon its reaction with BaP4H (Figure 3A,B and Table 1). The relatively low precursor intensities (a proxy for abundance) for six other 
unique prolyl hydroxylation sites in BaEFTu are minor hydroxylation events relative to Pro 54. A homology model of BaEFTu generated on the basis of the crystal structure of $P$. putida EFTu (PDB entry 4JOQ) shows different proline hydroxylation sites, and interestingly, Pro 54 is surface-exposed and located within the switch I loop region (Figure 3C).

To determine if the two proteins interact with each other, the thermodynamic parameters associated with the binding of BaEFTu to BaP4H were evaluated by ITC (Figure 3D). While the affinity of the BaP4H-BaEFTu complex is relatively weak $\left(K_{\mathrm{d}}=13 \pm 2 \mu \mathrm{M}\right)$, the interaction is accompanied by a $\Delta G^{\circ}$ of $-4.77 \mathrm{kcal} / \mathrm{mol}$ and a $\Delta S$ of $2.63 \mathrm{cal} \mathrm{mol}^{-1} \mathrm{~K}^{-1}$, with both entropy and enthalpy $(\Delta H=-5.5 \mathrm{kcal} / \mathrm{mol})$ changes contributing favorably to complex formation.

To identify if BaP4H forms a stable complex with BaEFTu, gel filtration was used to resolve the complex from individual protein solutions. The elution profiles monitored for $\mathrm{BaP} 4 \mathrm{H}$ and BaEFTu in buffer containing $200 \mathrm{mM} \mathrm{NaCl}$ showed a dimer and dimer-monomer equilibrium for each protein in solution, respectively (Figure 4A, traces $\mathrm{c}$ and d, and Table $3)$.

When the two proteins were mixed in an equimolar ratio and allowed to form a complex, the elution profile displayed a predominant peak at $14.7 \mathrm{~mL}$ and a shoulder at $14 \mathrm{~mL}$ (Table 3 and Figure 4A, trace b). To observe if salt has any effect on complex formation, equimolar solutions of $\mathrm{BaP} 4 \mathrm{H}$ and $\mathrm{BaEFTu}$ were allowed to form a complex in the same buffer in the absence of $\mathrm{NaCl}$. Indeed, the two proteins form a 1:1 heterodimeric complex that elutes as a symmetrical peak at $14.9 \mathrm{~mL}$ (Figure $4 \mathrm{~A}$, trace a). These results suggest that the presence of $\mathrm{NaCl}$ slightly shifts the peak, consistent with a heterodimer, into a profile with a prominent peak corresponding to a MW of $55 \mathrm{kDa}$ and a new high-MW ( $\sim 84 \mathrm{kDa})$ species that appeared as a shoulder (Table 3 and Figure 4A, trace b).

Subsequent SDS-PAGE gel analysis of the peak fractions of the complex in the absence of salt showed an even distribution of the two proteins at MWs of $\sim 24$ and $45 \mathrm{kDa}$ corresponding to BaP4H and BaEFTu, respectively (Figure $4 \mathrm{~B}$ ). The elution fractions of the complex in $200 \mathrm{mM} \mathrm{NaCl}$ displayed an uneven BaP4H:BaEFTu ratio on the SDS-PAGE gel, indicating that a higher ionic strength likely weakens the interaction between the two proteins (Figure 4C). Furthermore, on the basis of the gel, the shoulder corresponding to the high-MW species (in Figure 4A, trace b, and Table 3) was exclusively identified as BaEFTu (Figure 4C, lane 1). Thus, the MWs for the $\mathrm{BaP} 4 \mathrm{H}-\mathrm{BaEFTu}$ heterodimeric complex obtained by gel filtration are similar in the presence $(55 \mathrm{kDa})$ and absence $(51 \mathrm{kDa})$ of salt and consistent with that estimated from SEC-SAXS (54 kDa) discussed below.

\section{Solution Structural Studies of the BaP4H-BaEFTu Complex, Free BaP4H, and BaEFTu}

To gain stoichiometric and structural insight into the BaP4H-BaEFTu complex, we performed solution-based structural analysis using SEC-coupled small-angle X-ray scattering (SEC-SAXS). To examine the formation of the complex between $\mathrm{BaP} 4 \mathrm{H}$ and $\mathrm{BaEFTu}$, scattering data were collected around the peak from the gel-filtration chromatogram (Figure S3) in free and complex states. The elution profiles for all three species (free BaP4H, free BaEFTu, and complex) in the SEC portion of the SEC-SAXS data 
were distinctive, consistent with the in-house gel-filtration profiles described above (Figure $4 \mathrm{~A}$ and Figure S3). In the absence of salt, when equimolar solutions of $\mathrm{BaP} 4 \mathrm{H}$ and BaEFTu were allowed to form a complex, a distinct shift in the profile was observed (Figure S3). The symmetrical nature of this peak is also consistent with that observed in the in-house gelfiltration elution profile for a heterodimeric complex in the absence of salt (Figure 4A, trace a, and Figure S3). Prior to the characterization of the complex of two proteins, SAXS measurements were taken with free $\mathrm{BaP} 4 \mathrm{H}$ and BaEFTu. Analysis of the scattering profiles obtained as Guinier curves by plotting $\ln (I)$ versus $q^{2}$, where $I$ is the scattering intensity and $q$ is a function of scattering angle, showed linearity in the low $q$ range, indicating the absence of any aggregation and interparticle effects (Figure 5A,B). Guinier approximation resulted in radii of gyration $\left(R_{\mathrm{g}}\right)$ of $\sim 25, \sim 26$, and $\sim 28 \AA$ for $\mathrm{BaP} 4 \mathrm{H}, \mathrm{BaEFTu}$, and the $\mathrm{BaP} 4 \mathrm{H}-\mathrm{BaEFTu}$ complex, respectively. The theoretical $R_{\mathrm{g}}$ values calculated using CRYSOL, ${ }^{61}$ for the crystal structure of the BaP4H dimer (PDB entry 5V7Y), a homology model of BaEFTu generated from the crystal structure of $P$. putida EFTu (PDB entry 4JOQ), and a 1:1 complex of the P. putida PPHD-EFTu crystal structure (PDB entry 4IW3), were consistent ( $\sim 23, \sim 24$, and $\sim 26 \AA$, respectively) with the experimental values (Supporting Table 1). The maximum dimension $\left(D_{\max }\right)$ was determined by converting the scattering profiles into pair-distance distributions, $P(r)$. The $D_{\max }$ values for free $\mathrm{BaP} 4 \mathrm{H}$ and $\mathrm{BaEFTu}$ are 78 and $91 \AA$, respectively, whereas the mixture of two proteins had a $D_{\max }$ extending to $110 \AA$, suggestive of complex formation (Figure 5C). Furthermore, the $R_{\mathrm{g}}$ values calculated by the $P(r)$ for the individual proteins ( 25 and $26 \AA$, respectively) and the complex ( $29 \AA$ ) agree well with that obtained from Guinier analysis (Supporting Table 1).

The MWs estimated from DAMMIF, an ab initio shape reconstruction program, were $\sim 48$ and $\sim 43 \mathrm{kDa}$ for $\mathrm{BaP} 4 \mathrm{H}$ and BaEFTu, respectively, and were in good agreement with the calculated values of $49.4 \mathrm{kDa}$ for the $\mathrm{BaP} 4 \mathrm{H}$ dimer and $45.5 \mathrm{kDa}$ for monomeric BaEFTu, respectively, determined from the corresponding protein sequences (Table 3). The lowresolution DAMMIF envelope for $\mathrm{BaP} 4 \mathrm{H}$ fits well with the crystal structure of dimeric $\mathrm{BaP} 4 \mathrm{H}$ (Figure 6A). The structure of BaEFTu is not determined but exists as a monomerdimer equilibrium in solution (Figure 4A, trace d) ${ }^{27}$ The homology model of BaEFTu obtained from the crystal structure of $P$. putida EFTu (PDB entry 4JOQ) can be superimposed with the DAMMIF envelope for BaEFTu (Figures 3C and 6B). Theoretical scattering curves calculated using CRYSOL for BaEFTu and BaP4H dimer fit well ( $\chi^{2} \sim$ 1.6) with the experimental scattering profiles for the individual proteins (Figure 5D,E). The SAXS envelope of the BaP4H-BaEFTu complex matches well with the crystal structure of a 1:1 complex of $P$. putida PPHD with EFTu (PDB entry 4IW3) (Figure 6C). ${ }^{27}$ Slight deviations in the fit may be attributable to hypermobile regions signified by higher crystallographic $B$ factors or subtle conformational changes in solution that cannot be observed in the resolution limits of SAXS. ${ }^{50}$ Furthermore, the theoretical scattering curve calculated for the heterodimeric complex matches $\left(\chi^{2}=6.3\right)$ with the observed scattering profile for the 1:1 complex (Figure 5F). The relatively high $\chi^{2}$ value for the $\mathrm{BaP} 4 \mathrm{H}-$ BaEFTu complex may be attributable to differences between the crystal structure used (PPHD-EFTu, PDB entry 4IW3) and the protein samples that produced the experimental scattering curve. Comparison of the calculated scattering curve of the $\mathrm{BaP} 4 \mathrm{H}$ dimer with the experimental scattering profile of the 1:1 complex shows a poor fit $\left(\chi^{2}=18.2\right)$ (Figure S4), 
further confirming the formation of a heterodimeric complex. The relatively large difference between the predicted MW of $\sim 54 \mathrm{kDa}$ [by DAMMIF (Table 3)] and the theoretical value (70.2 $\mathrm{kDa}$, based on sequence) for a 1:1 complex indicates the compactness of the $\mathrm{BaP} 4 \mathrm{H}-$ BaEFTu heterodimeric complex in solution. Nonetheless, these results are strongly suggestive of a subunit dissociation of the $\mathrm{BaP} 4 \mathrm{H}$ dimer upon interaction with BaEFTu at the concentrations used for SEC-SAXS experiments $(\sim 80 \mu \mathrm{M})$.

\section{The BaP4H Structure Reveals a Conformational Change Closing the Substrate Binding Loop}

Our previously determined $\mathrm{BaP} 4 \mathrm{H}$ structures in the presence of various cofactors illustrated conformational changes at the active site defining open and closed forms of the enzyme. ${ }^{23,28}$ The $\mathrm{Co}(\mathrm{II})-\mathrm{BaP} 4 \mathrm{H}$ structure presented here provides insight into possible substrate recognition as the residues (amino acids 62-67) within the substrate binding loop (SBL) region are ordered.

The crystal structure of $\mathrm{Co}(\mathrm{II})-\mathrm{BaP} 4 \mathrm{H}$ in complex with $a \mathrm{KG}$ or trifluoroacetic acid (TFA) was obtained by co-crystallizing apo-BaP4H in the presence of $\mathrm{Co}(\mathrm{II}), a \mathrm{KG}$, and the BaEFTu-9 peptide. $\mathrm{Co}$ (II)-BaP4H is catalytically inert, and the structure determined at 2.05 $\AA$ A resolution contains four molecules in the asymmetric unit with two BaP4H dimers. Each chain is similar overall with a root-mean-square deviation of $0.2 \AA$ over $155 \mathrm{C} a$ atoms. Although the protein was co-crystallized with the BaEFTu-9 peptide, no density for the peptide was visible in any of the active sites. Instead, chain B showed electron density for residues 62-67 of the SBL from a symmetry-mate of chain A bound near its active site (Figure 7).

Structural alignment of chains A and B of $\mathrm{Co}(\mathrm{II})-\mathrm{BaP} 4 \mathrm{H}$ with apo-BaP4H chain A (PDB entry 5IAT) displayed differences in the SBL region (residues 62-82), with chain B being the only chain that has a fully closed SBL (Figure 7A). In apo-BaP4H, the SBL is placed in an open form away from the active site, but in chain $\mathrm{A}$ of $\mathrm{Co}(\mathrm{II})-\mathrm{BaP} 4 \mathrm{H}$, it is oriented toward the protein surface and adopts a partially open conformation. In chain B, the SBL swings inward and is positioned above the active site, adopting a fully closed conformation, which could be due to the symmetry loop region interacting with the active site. In fact, closing of the active site is required for protecting high-valent iron-oxo species formed during catalysis in this family of enzymes. Thus, a fully closed SBL indicates that BaP4H could use an induced-fit mechanism for catalysis as observed previously for other mononuclear iron enzymes, such as hydroxypropylphosphonic acid epoxidase. ${ }^{51,52}$ Thus, chain $\mathrm{B}$ of the $\mathrm{Co}(\mathrm{II})-\mathrm{BaP} 4 \mathrm{H}$ structure presented here mimics the "ready" state of the enzyme, and chain A represents the precatalytic state.

In $\mathrm{Co}(\mathrm{II})-\mathrm{BaP} 4 \mathrm{H}$, the active site of each monomer had either $a \mathrm{KG}$ or TFA bound (Figure 7B,C). The source of TFA is from the synthetic peptide used in crystallization. With the exception of the active site in chain B that contains $a \mathrm{KG}$ bound to cobalt, chains A, C, and $\mathrm{D}$ all contain TFA in the space where the C5 carboxylate end of $a \mathrm{KG}$ is generally located (Figure 7B,C). The active sites with TFA contain imidazole bound to the Co(II) ion in addition to the protein residues (His 127, Asp 129, and His 193), resulting in a fourcoordinate $\mathrm{Co}(\mathrm{II})$ center with tetrahedral geometry. Unlike previous $a \mathrm{KG}$ - and malonate- 
bound forms of $\mathrm{Co}$ (II)-BaP4H, TFA does not bind to the active site metal ion but makes the same hydrogen bonds through its carboxylate end to Tyr 118 and Thr 159 and forms a salt bridge with Lys 203 (Figure 7B). The active site in chain B with bound $a \mathrm{KG}$ has an open site on the five-coordinate $\mathrm{Co}$ (II) center with trigonal bipyramidal geometry (Figure 7C). The $\mathrm{Co}(\mathrm{II})-\mathrm{BaP} 4 \mathrm{H}$ structure contains a loop region encompassing residues 62-68 of a symmetry molecule of chain A bound in the active site of chain B (Figure 7D). The presence of a symmetry loop (residues 62-68) in chain B resulting due to a crystallization artifact serves as a model for how a peptide binds in the active site of $\mathrm{BaP} 4 \mathrm{H}$ and was used to dock the actual BaEFTu-9 peptide. Interestingly, the symmetry loop is anchored into the active site by a number of different hydrogen bond interactions (Figure 7D), some of which are similar to that observed in the peptide docking model described below.

\section{Peptide Docking}

In the absence of a crystal structure of the $\mathrm{BaP} 4 \mathrm{H}-\mathrm{BaEFTu}$ complex and to gain insight into their interaction, the BaEFTu-9 peptide was docked into the $\mathrm{Co}(\mathrm{II})-\mathrm{BaP} 4 \mathrm{H}$ structure. Chain $\mathrm{B}$ was used for the docking as it has bound $a \mathrm{KG}$ and contains a fully closed SBL, with the loop region from a symmetry molecule protruding into the active site (Figure 7D,E). The Pro in the DAAPEERER docked peptide (Pro 54 in BaEFTu) is in a C-4 endo conformation with $\mathrm{C}-4$ of the pyrrolidine ring in the proximity $(\sim 5 \AA)$ of the metal center poised for hydroxylation (Figure 7E). BaP4H shares a conserved tyrosine (Tyr 124) with other P4Hs [PPHD, Tyr 121; PHD2, Tyr 310; Chlamydomonas reinhardtii P4H (CrP4H), Tyr 140], where the hydroxyl group is directed at the amide of the proline (Figure 7E). In addition, these P4Hs contain a conserved arginine (BaP4H, Arg 142; PPHD, Arg 134; PHD2, Arg $322 ; \mathrm{CrP} 4 \mathrm{H}, \mathrm{Arg} 161$ ) that is hydrogen bonded with the carbonyl of the proline. This Arg in $\mathrm{BaP} 4 \mathrm{H}$ also interacts with the carbonyl oxygen of Lys 63 in the bound symmetry loop (Figure 7D). Other interactions between $\mathrm{BaP} 4 \mathrm{H}$ and the peptide include hydrogen bonds between Tyr 128 and Asp 51, Asp 77 and Ala 52, Arg 79 and Glu 55, and Ser 137 and Glu 56 (Figure 7E). It is interesting that the backbone of Arg 57 in the modeled peptide occupies the same space as Arg 66 from the symmetry loop, indicating that this arginine probably plays a structural role.

\section{DISCUSSION}

The P4Hs share some common substrate recognition motifs, such as the conserved residues interacting with specific sites of the substrate despite their diverse biological origins $\mathrm{s}^{4,25}$ (Figure S1). While $\mathrm{BaP} 4 \mathrm{H}$ was previously thought to belong to the group of collagen $\mathrm{P} 4 \mathrm{Hs}$, the physiological substrate for $\mathrm{BaP} 4 \mathrm{H}$ has not been established. The proteome of $B$. anthracis contains proteins with collagen-like motifs of (G-P-T) ${ }_{n}$ repeats. The (G-P-T) repeat is most common among bacterial CSMs versus the (P-P-G) ${ }_{n}$ repeats found in humans. ${ }^{15} \mathrm{BaP} 4 \mathrm{H}$ was shown to hydroxylate both the $\mathrm{X}$ and $\mathrm{Y}$ positions of (X-Y-Gly) peptides, where $\mathrm{X}$ and $\mathrm{Y}$ were both proline. ${ }^{23}$ Although $\mathrm{BaP} 4 \mathrm{H}$ could theoretically hydroxylate the proline in (G-P-T) repeats, glycosylation of the threonine residue has been shown to stabilize triple helices similar to prolyl hydroxylation and is a common occurrence for collagen-like proteins in $B$. anthracis. ${ }^{53-55}$ With the knowledge that collagen-like proteins are relatively rare among prokaryotes and the bacterial CSMs do not have the same 
need for stabilization by hydroxylation as in humans, we sought to examine if $\mathrm{BaP} 4 \mathrm{H}$ could target the highly conserved BaEFTu from B. anthracis, given the precedence of EFTu acting as a substrate of PPHD.

BaP4H and PPHD are two known bacterial prolyl hydroxylases that act on peptidyl proline residues instead of free proline. BaP4H is unusual among bacterial $\mathrm{P} 4 \mathrm{Hs}$ in that it exhibits promiscuity in substrate recognition and is structurally and functionally related to the animal PHDs as well as to human collagen $\mathrm{P} 4 \mathrm{H}$. While we have shown that $\mathrm{BaP} 4 \mathrm{H}$ hydroxylates both BaEFTu and collagen-like (P-P-G) $)_{5,10}$ peptides, the much tighter binding affinity of BaP4H for the BaEFTu-9 peptide $\left(K_{\mathrm{d}}=0.077 \mu \mathrm{M}\right)$ than for the collagen-like peptides $\left(K_{\mathrm{d}} \sim\right.$ $0.5 \mu \mathrm{M})^{23}$ supports BaEFTu as a more favorable substrate. Although all $\mathrm{P} 4 \mathrm{Hs}$ share the conserved double-stranded $\beta$-helix core domain, substrate specificity is achieved by additional factors such as a SBL and substrate three-dimensional conformation. ${ }^{56,57} \mathrm{~A}$ common three-dimensional structure of proline-containing regions is the poly-L-proline type II (PPII) helix conformation. The PPII helices are known to mediate protein-protein interactions and are found in many different proline recognition domains. ${ }^{16,58}$ Currently, crystal structures of three different $\mathrm{P} 4 \mathrm{Hs}$ have been determined with their substrate bound. ${ }^{22,27,57}$ On the basis of these structures, it is believed that while the primary sequences of the substrates do not contain similarities, the enzyme-bound conformations of the peptide substrates are all closely matched and adopt a PPII helical conformation. Here, a peptide-bound complex of $\mathrm{Co}$ (II)-BaP4H was made adventitiously by a crystal packing artifact that resulted in a closed conformational state (Figure 7A,D). Nonetheless, this "closed" active site could be used as a model for docking the BaEFTu-9 peptide. In BaP4H, the peptide substrate binding groove lined with aromatic and charged residues is most likely responsible for the tight binding affinity of the BaEFTu-9 peptide (Figure 7D,E). Docking of this 9-mer peptide with the $\mathrm{Co}(\mathrm{II})-\mathrm{BaP} 4 \mathrm{H}$ crystal structure showed the correct C-4 endo conformation for Pro 54 that would lead to the formation of $4 R$-Hyp, similar to that observed for other P4H complexes with their substrates: PPHD, ${ }^{27} \mathrm{PHD} 2,{ }^{25}$ and $\mathrm{CrP} 4 \mathrm{H} .{ }^{22}$ This model is supported by the MS data that show hydroxylation of Pro 54 in the BaEFTu-9 peptide (Figure 2C).

Our tandem LC-MS/MS data in concert with biophysical studies have revealed that $\mathrm{BaP} 4 \mathrm{H}$ interacts with and site-specifically hydroxylates proline residues in BaEFTu (Table 1). While the interaction between BaP4H and BaEFTu is relatively weak with a $K_{\mathrm{d}}$ of $\sim 13 \mu \mathrm{M}$, the complex formation is driven by both entropy $(T \Delta S=0.73 \mathrm{kcal} / \mathrm{mol})$ and enthalpy $(\Delta H=$ $-5.5 \mathrm{kcal} / \mathrm{mol})$. The SEC-SAXS results reveal a 1:1 BaP4H-BaEFTu heterodimeric complex, suggesting disruption of the $\mathrm{BaP} 4 \mathrm{H}$ dimeric subunit upon association with BaEFTu (Figure 6). In the absence of a crystal structure of the BaP4H-BaEFTu complex, our solution structure matches well with the crystal structure of a 1:1 complex between $P$. putida EFTu and the hydroxylase $\mathrm{PPHD}_{\text {putida }}{ }^{27}$ The sensitivity to ionic strength on gel filtration indicates the presence of one or more salt bridges contributing to the stability of the 1:1 complex (Figure 4). The MS results with full-length BaEFTu showed preferential hydroxylation of Pro 54. The same proline in P. putida EFTu was hydroxylated by PPHD $_{\text {putida }}$ in a bottom-up approach in which synthetic peptides were used to cover prolinecontaining sequences of the EFTu protein. ${ }^{27}$ Interestingly, PPHD $_{\text {putida }}$ selectively hydroxylated only Pro 54 among all proline sites in EFTu peptides. However, BaP4H 
hydroxylated additional proline residues in full-length BaEFTu (Table 1). On the basis of a homology model of BaEFTu, all seven hydroxylated proline residues are located in different loop regions that are mostly surface-exposed (Figure 3C). While additional experiments, including crystal structure and site-directed mutagenesis of BaEFTu, are necessary to determine the structural and functional role of these hydroxylation sites, it is interesting that surface-exposed prolines in Arabidopsis thaliana EFTu are predicted to be utilized in defense response mechanisms and would serve as new targets for antibiotics that disrupt bacterial protein translation..$^{59,60}$

\section{CONCLUSIONS}

The results described here revealed that $\mathrm{BaP} 4 \mathrm{H}$ interacts with $\mathrm{BaEFTu}$ and hydroxylates unique proline sites, thus expanding its substrate recognition ability beyond CSMs with a possible role in the $B$. anthracis translation process. Furthermore, we have demonstrated that $\mathrm{BaP} 4 \mathrm{H}$ forms a 1:1 heterodimeric complex with BaEFTu in solution, and the interaction between the two proteins results in disruption of $\mathrm{BaP} 4 \mathrm{H}$ dimeric subunits. Additional studies to determine the X-ray crystal structure of active $\mathrm{Fe}(\mathrm{II})-\mathrm{BaP} 4 \mathrm{H}$ with substrate peptides bound are currently underway, which would allow the visualization of specific molecular interactions for peptide binding, site-specific catalysis, and provide an understanding of the diverse substrate recognition. In conclusion, our studies suggest the promiscuity of $\mathrm{BaP} 4 \mathrm{H}$ within the bacterial clade in that it is structurally and functionally related to the HIF-PHDs and collagen P4Hs. In future studies, it would be of interest to determine if hydroxylated BaEFTu exists in vivo and identify the functional role of this modification in $B$. anthracis. Moreover, $\mathrm{O}_{2}$ saturation of $\mathrm{BaP} 4 \mathrm{H}$ is yet to be determined, which may provide insight into its oxygen sensing ability and will aid in understanding if $\mathrm{BaP} 4 \mathrm{H}$ expression modulates the bacterial translational process in an $\mathrm{O}_{2}$-dependent manner, similar to an $\mathrm{O}_{2}$ sensor such as the HIF-PHDs.

\section{Supplementary Material}

Refer to Web version on PubMed Central for supplementary material.

\section{Acknowledgments}

The authors are grateful to Dr. Ryan Kunz and Prof. Steven Gygi at the Thermo Fisher Scientific Center for Multiplexed Proteomics at Harvard Medical School for helping us with the mass spectrometry data collection and analysis. X-ray and SEC-SAXS data were collected at the Advanced Light Source (ALS) and Advanced Photon Source (APS), respectively. Support for the synchrotron sources is provided by the U.S. Department of Energy.

Funding

M.D. was supported by The University of Iowa College of Liberal Arts and Sciences and funding from the National Science Foundation (CLP 1506181). The SAXS experiment was supported by Grant P41 GM103622 from the National Institute of General Medical Sciences (NIGMS) of the National Institutes of Health. Use of the Pilatus 1M detector was provided by Grant 1S10OD018090-01 from NIGMS.

\section{ABBREVIATIONS}

P4H prolyl 4-hydroxylase 


$\begin{array}{ll}\text { Hyp } & \text { hydroxyproline } \\ a \text { KG } & a \text {-ketoglutarate } \\ \text { BaEFTu } & \text { B. anthracis elongation factor Tu } \\ \text { SBL } & \text { substrate binding loop } \\ \text { LC-MS/MS liquid chromatography-mass spectrometry } \\ \text { SEC } & \text { size-exclusion chromatography } \\ \text { SAXS } & \text { small-angle X-ray scattering } \\ \boldsymbol{R}_{\mathbf{g}} & \text { radius of gyration } \\ \boldsymbol{D}_{\text {max }} & \text { maximum dimension } \\ \boldsymbol{P}(\boldsymbol{r}) & \text { pair-distance distribution } \\ \text { TFA } & \text { trifluoroacetic acid } \\ \text { PDB } & \text { Protein Data Bank }\end{array}$

\section{References}

1. Ploumakis A, Coleman ML. OH, the Places You'll Go! Hydroxylation, Gene Expression, and Cancer. Mol Cell. 2015; 58(5):729-41. [PubMed: 26046647]

2. Semenza GL. Oxygen sensing, hypoxia-inducible factors, and disease pathophysiology. Annu Rev Pathol: Mech Dis. 2014; 9:47-71.

3. Kant R, Bali A, Singh N, Jaggi AS. Prolyl 4 hydroxylase: a critical target in the pathophysiology of diseases. Korean J Physiol Pharmacol. 2013; 17(2):111-20. [PubMed: 23626472]

4. Gorres KL, Raines RT. Prolyl 4-hydroxylase. Crit Rev Biochem Mol Biol. 2010; 45(2):106-24. [PubMed: 20199358]

5. Myllyharju J. Prolyl 4-hydroxylases, key enzymes in the synthesis of collagens and regulation of the response to hypoxia, and their roles as treatment targets. Ann Med. 2008; 40(6):402-17. [PubMed: 19160570]

6. Hausinger RP. FeII/alpha-ketoglutarate-dependent hydroxylases and related enzymes. Crit Rev Biochem Mol Biol. 2004; 39(1):21-68. [PubMed: 15121720]

7. Aik W, McDonough MA, Thalhammer A, Chowdhury R, Schofield CJ. Role of the jelly-roll fold in substrate binding by 2-oxoglutarate oxygenases. Curr Opin Struct Biol. 2012; 22(6):691-700. [PubMed: 23142576]

8. Loenarz C, Schofield CJ. Expanding chemical biology of 2-oxoglutarate oxygenases. Nat Chem Biol. 2008; 4(3):152-6. [PubMed: 18277970]

9. Clifton IJ, McDonough MA, Ehrismann D, Kershaw NJ, Granatino N, Schofield CJ. Structural studies on 2-oxoglutarate oxygenases and related double-stranded beta-helix fold proteins. J Inorg Biochem. 2006; 100(4):644-69. [PubMed: 16513174]

10. Costas M, Mehn MP, Jensen MP, Que L Jr. Dioxygen activation at mononuclear nonheme iron active sites: enzymes, models, and intermediates. Chem Rev. 2004; 104(2):939-86. [PubMed: 14871146]

11. McDonough MA, Loenarz C, Chowdhury R, Clifton IJ, Schofield CJ. Structural studies on human 2-oxoglutarate dependent oxygenases. Curr Opin Struct Biol. 2010; 20(6):659-72. [PubMed: 20888218]

12. Schofield CJ, Zhang Z. Structural and mechanistic studies on 2-oxoglutarate-dependent oxygenases and related enzymes. Curr Opin Struct Biol. 1999; 9(6):722-31. [PubMed: 10607676] 
13. Markolovic S, Wilkins SE, Schofield CJ. Protein Hydroxylation Catalyzed by 2-Oxoglutaratedependent Oxygenases. J Biol Chem. 2015; 290(34):20712-22. [PubMed: 26152730]

14. Anantharajan J, Koski MK, Kursula P, Hieta R, Bergmann U, Myllyharju J, Wierenga RK. The structural motifs for substrate binding and dimerization of the alpha subunit of collagen prolyl 4hydroxylase. Structure. 2013; 21(12):2107-18. [PubMed: 24207127]

15. Rasmussen M, Jacobsson M, Bjorck L. Genome-based identification and analysis of collagenrelated structural motifs in bacterial and viral proteins. J Biol Chem. 2003; 278(34):32313-6. [PubMed: 12788919]

16. Adzhubei AA, Sternberg MJ, Makarov AA. Polyproline-II helix in proteins: structure and function. J Mol Biol. 2013; 425(12):2100-32. [PubMed: 23507311]

17. Vitagliano L, Berisio R, Mazzarella L, Zagari A. Structural bases of collagen stabilization induced by proline hydroxylation. Biopolymers. 2001; 58(5):459-64. [PubMed: 11241217]

18. Myllyharju J. HIF prolyl 4-hydroxylases and their potential as drug targets. Curr Pharm Des. 2009; 15(33):3878-85. [PubMed: 19671043]

19. Romero-Ruiz A, Bautista L, Navarro V, Heras-Garvin A, March-Diaz R, Castellano A, GomezDiaz R, Castro MJ, Berra E, Lopez-Barneo J, Pascual A. Prolyl hydroxylase-dependent modulation of eukaryotic elongation factor 2 activity and protein translation under acute hypoxia. $\mathrm{J}$ Biol Chem. 2012; 287(12):9651-8. [PubMed: 22308030]

20. Longbotham JE, Levy C, Johannissen LO, Tarhonskaya H, Jiang S, Loenarz C, Flashman E, Hay S, Schofield CJ, Scrutton NS. Structure and Mechanism of a Viral Collagen Prolyl Hydroxylase. Biochemistry. 2015; 54(39):6093-105. [PubMed: 26368022]

21. Wong BW, Kuchnio A, Bruning U, Carmeliet P. Emerging novel functions of the oxygen-sensing prolyl hydroxylase domain enzymes. Trends Biochem Sci. 2013; 38(1):3-11. [PubMed: 23200187]

22. Koski MK, Hieta R, Hirsila M, Ronka A, Myllyharju J, Wierenga RK. The crystal structure of an algal prolyl 4-hydroxylase complexed with a proline-rich peptide reveals a novel buried tripeptide binding motif. J Biol Chem. 2009; 284(37):25290-301. [PubMed: 19553701]

23. Schnicker NJ, Dey M. Bacillus anthracis Prolyl 4-Hydroxylase Modifies Collagen-like Substrates in Asymmetric Patterns. J Biol Chem. 2016; 291(25):13360-74. [PubMed: 27129244]

24. Culpepper MA, Scott EE, Limburg J. Crystal structure of prolyl 4-hydroxylase from Bacillus anthracis. Biochemistry. 2010; 49(1):124-33. [PubMed: 19947658]

25. Chowdhury R, Leung IK, Tian YM, Abboud MI, Ge W, Domene C, Cantrelle FX, Landrieu I, Hardy AP, Pugh CW, Ratcliffe PJ, Claridge TD, Schofield CJ. Structural basis for oxygen degradation domain selectivity of the HIF prolyl hydroxylases. Nat Commun. 2016; 7:12673. [PubMed: 27561929]

26. Gupta N, Tanner S, Jaitly N, Adkins JN, Lipton M, Edwards R, Romine M, Osterman A, Bafna V, Smith RD, Pevzner PA. Whole proteome analysis of post-translational modifications: applications of mass-spectrometry for proteogenomic annotation. Genome Res. 2007; 17(9):1362-77. [PubMed: 17690205]

27. Scotti JS, Leung IK, Ge W, Bentley MA, Paps J, Kramer HB, Lee J, Aik W, Choi H, Paulsen SM, Bowman LA, Loik ND, Horita S, Ho CH, Kershaw NJ, Tang CM, Claridge TD, Preston GM, McDonough MA, Schofield CJ. Human oxygen sensing may have origins in prokaryotic elongation factor Tu prolyl-hydroxylation. Proc Natl Acad Sci U S A. 2014; 111(37):13331-6. [PubMed: 25197067]

28. Schnicker NJ, Dey M. Structural analysis of cofactor binding for a prolyl 4-hydroxylase from the pathogenic bacterium Bacillus anthracis. Acta Crystallogr, Sect D: Struct Biol. 2016; 72(5):675681. [PubMed: 27139630]

29. Miller MA, Scott EE, Limburg J. Expression, purification, crystallization and preliminary X-ray studies of a prolyl-4-hydroxylase protein from Bacillus anthracis. Acta Crystallogr, Sect F: Struct Biol Cryst Commun. 2008; 64(9):788-791.

30. Brummett AE, Schnicker NJ, Crider A, Todd JD, Dey M. Biochemical, Kinetic, and Spectroscopic Characterization of Ruegeria pomeroyi DddW-A Mononuclear Iron-Dependent DMSP Lyase. PLoS One. 2015; 10(5):e0127288. [PubMed: 25993446] 
31. Huttlin EL, Jedrychowski MP, Elias JE, Goswami T, Rad R, Beausoleil SA, Villen J, Haas W, Sowa ME, Gygi SP. A tissue-specific atlas of mouse protein phosphorylation and expression. Cell. 2010; 143(7):1174-89. [PubMed: 21183079]

32. Mathew E, Mirza A, Menhart N. Liquid-chromatography-coupled SAXS for accurate sizing of aggregating proteins. J Synchrotron Radiat. 2004; 11(4):314-318. [PubMed: 15211037]

33. Konarev PV, Volkov VV, Sokolova AV, Koch MHJ, Svergun DI. PRIMUS: a Windows PC-based system for small-angle scattering data analysis. J Appl Crystallogr. 2003; 36(5):1277-1282.

34. Petoukhov MV, Franke D, Shkumatov AV, Tria G, Kikhney AG, Gajda M, Gorba C, Mertens HD, Konarev PV, Svergun DI. New developments in the ATSAS program package for small-angle scattering data analysis. J Appl Crystallogr. 2012; 45(2):342-350. [PubMed: 25484842]

35. Putnam CD, Hammel M, Hura GL, Tainer JA. X-ray solution scattering (SAXS) combined with crystallography and computation: defining accurate macromolecular structures, conformations and assemblies in solution. Q Rev Biophys. 2007; 40(03):191-285. [PubMed: 18078545]

36. Franke D, Svergun DI. DAMMIF, a program for rapid ab-initio shape determination in small-angle scattering. J Appl Crystallogr. 2009; 42(2):342-346. [PubMed: 27630371]

37. Humphrey W, Dalke A, Schulten K. VMD: visual molecular dynamics. J Mol Graphics. 1996; 14(1):33-38.

38. Kozin MB, Svergun DI. Automated matching of high- and low-resolution structural models. J Appl Crystallogr. 2001; 34:33-41.

39. Kabsch W. Xds. Acta Crystallogr, Sect D: Biol Crystallogr. 2010; 66(2):125-132. [PubMed: 20124692]

40. Evans PR, Murshudov GN. How good are my data and what is the resolution? Acta Crystallogr, Sect D: Biol Crystallogr. 2013; 69(7):1204-1214. [PubMed: 23793146]

41. McCoy AJ, Grosse-Kunstleve RW, Adams PD, Winn MD, Storoni LC, Read RJ. Phaser crystallographic software. J Appl Crystallogr. 2007; 40(4):658-674. [PubMed: 19461840]

42. Afonine PV, Grosse-Kunstleve RW, Echols N, Headd JJ, Moriarty NW, Mustyakimov M, Terwilliger TC, Urzhumtsev A, Zwart PH, Adams PD. Towards automated crystallographic structure refinement with phenix.refine. Acta Crystallogr, Sect D: Biol Crystallogr. 2012; 68(4): 352-367. [PubMed: 22505256]

43. Emsley P, Lohkamp B, Scott WG, Cowtan K. Features and development of Coot. Acta Crystallogr, Sect D: Biol Crystallogr. 2010; 66(4):486-501. [PubMed: 20383002]

44. The PyMOL Molecular Graphics System. Schrodinger, LLC; Portland, OR: 2015. version 1.8

45. Morin A, Eisenbraun B, Key J, Sanschagrin PC, Timony MA, Ottaviano M, Sliz P. Collaboration gets the most out of software. eLife. 2013; 2:e01456. [PubMed: 24040512]

46. Pierce BG, Wiehe K, Hwang H, Kim BH, Vreven T, Weng Z. ZDOCK server: interactive docking prediction of protein-protein complexes and symmetric multimers. Bioinformatics. 2014; 30(12): 1771-3. [PubMed: 24532726]

47. London N, Raveh B, Cohen E, Fathi G, Schueler-Furman O. Rosetta FlexPepDock web serverhigh resolution modeling of peptide-protein interactions. Nucleic Acids Res. 2011; 39(Web Server issue):W249-53. [PubMed: 21622962]

48. Raveh B, London N, Schueler-Furman O. Sub-angstrom modeling of complexes between flexible peptides and globular proteins. Proteins: Struct, Funct, Genet. 2010; 78(9):2029-40. [PubMed: 20455260]

49. Roy A, Kucukural A, Zhang Y. I-TASSER: a unified platform for automated protein structure and function prediction. Nat Protoc. 2010; 5(4):725-38. [PubMed: 20360767]

50. Zheng W, Tekpinar M. Accurate flexible fitting of high-resolution protein structures to small-angle $\mathrm{x}$-ray scattering data using a coarse-grained model with implicit hydration shell. Biophys J. 2011; 101(12):2981-91. [PubMed: 22208197]

51. Higgins LJ, Yan F, Liu P, Liu HW, Drennan CL. Structural insight into antibiotic fosfomycin biosynthesis by a mononuclear iron enzyme. Nature. 2005; 437(7060):838-44. [PubMed: 16015285]

52. Yun D, Dey M, Higgins LJ, Yan F, Liu HW, Drennan CL. Structural basis of regiospecificity of a mononuclear iron enzyme in antibiotic fosfomycin biosynthesis. J Am Chem Soc. 2011; 133(29): 11262-9. [PubMed: 21682308] 
53. Rety S, Salamitou S, Garcia-Verdugo I, Hulmes DJ, Le Hegarat F, Chaby R, Lewit-Bentley A. The crystal structure of the Bacillus anthracis spore surface protein BclA shows remarkable similarity to mammalian proteins. J Biol Chem. 2005; 280(52):43073-8. [PubMed: 16249180]

54. Daubenspeck JM, Zeng H, Chen P, Dong S, Steichen CT, Krishna NR, Pritchard DG, Turnbough CL Jr. Novel oligosaccharide side chains of the collagen-like region of BclA, the major glycoprotein of the Bacillus anthracis exosporium. J Biol Chem. 2004; 279(30):30945-53. [PubMed: 15152001]

55. Sylvestre P, Couture-Tosi E, Mock M. Polymorphism in the collagen-like region of the Bacillus anthracis BclA protein leads to variation in exosporium filament length. J Bacteriol. 2003; 185(5): 1555-63. [PubMed: 12591872]

56. Horita S, Scotti JS, Thinnes C, Mottaghi-Taromsari YS, Thalhammer A, Ge W, Aik W, Loenarz C, Schofield CJ, McDonough MA. Structure of the ribosomal oxygenase OGFOD1 provides insights into the regio- and stereoselectivity of prolyl hydroxylases. Structure. 2015; 23(4):639-52. [PubMed: 25728928]

57. Chowdhury R, McDonough MA, Mecinovic J, Loenarz C, Flashman E, Hewitson KS, Domene C, Schofield CJ. Structural basis for binding of hypoxia-inducible factor to the oxygen-sensing prolyl hydroxylases. Structure. 2009; 17(7):981-9. [PubMed: 19604478]

58. Berisio R, Vitagliano L. Polyproline and triple helix motifs in host-pathogen recognition. Curr Protein Pept Sci. 2012; 13(8):855-65. [PubMed: 23305370]

59. van Staalduinen LM, Jia Z. Post-translational hydroxylation by $2 \mathrm{OG} / \mathrm{Fe}(\mathrm{II})$-dependent oxygenases as a novel regulatory mechanism in bacteria. Front Microbiol. 2015; 5:798. [PubMed: 25642226]

60. Kunze G, Zipfel C, Robatzek S, Niehaus K, Boller T, Felix G. The N terminus of bacterial elongation factor Tu elicits innate immunity in Arabidopsis plants. Plant Cell. 2004; 16(12):34963507. [PubMed: 15548740]

61. Svergun DI, Barberato C, Koch MHJ. CRYSOL - a Program to Evaluate X-ray Solution Scattering of Biological Macromolecules from Atomic Coordinates. J Appl Crystallogr. 1995; 28:768-773. 


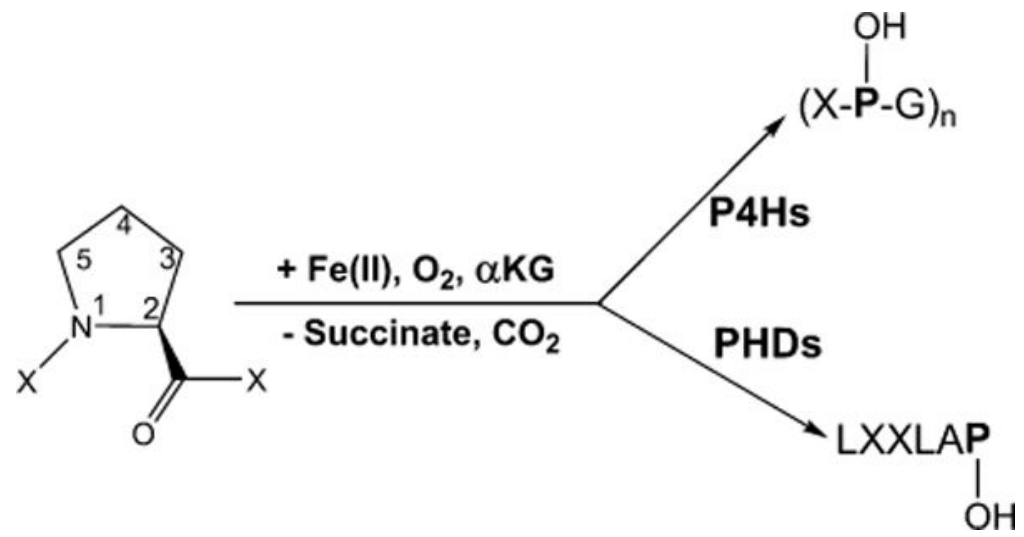

Figure 1.

Prolyl hydroxylation reaction catalyzed by PHDs and P4Hs. PHDs are known to hydroxylate prolyl residues in the LXXLAP motif of HIF-1 $a$, but P4Hs hydroxylate collagen-like (X-P$\mathrm{G})_{n}$ repeats. 
A

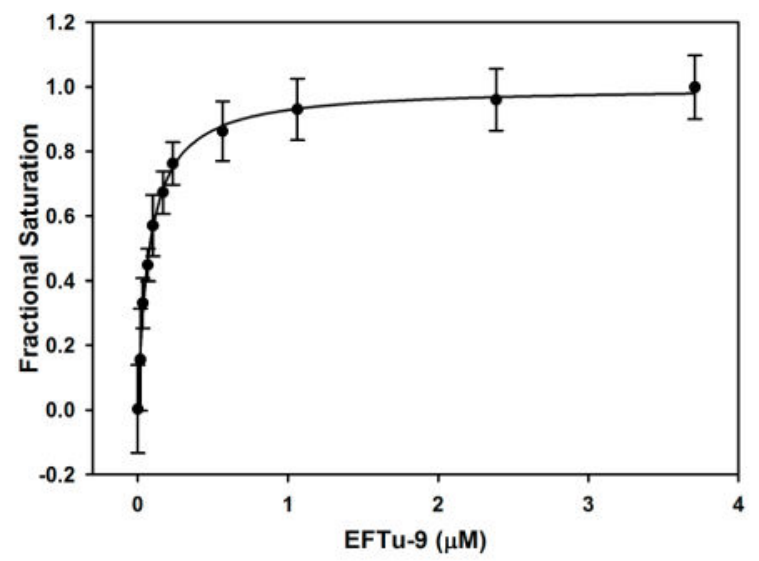

B

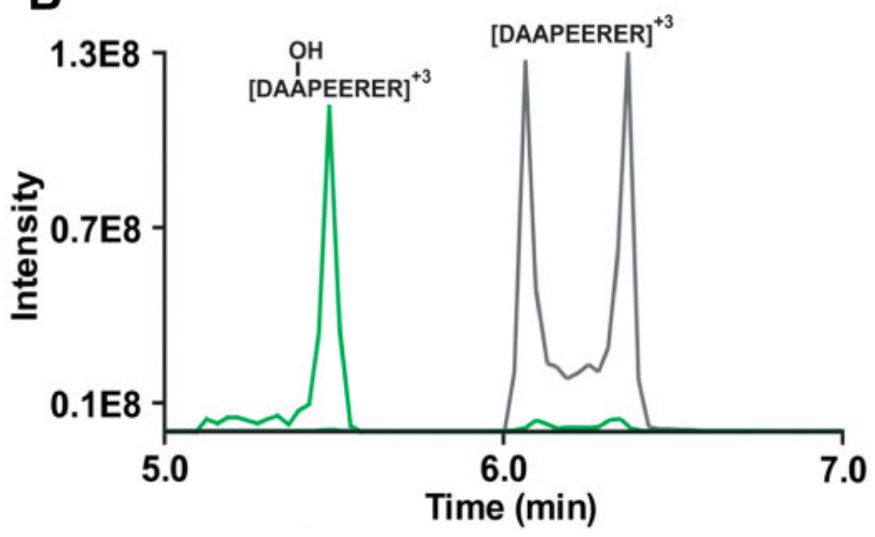

C

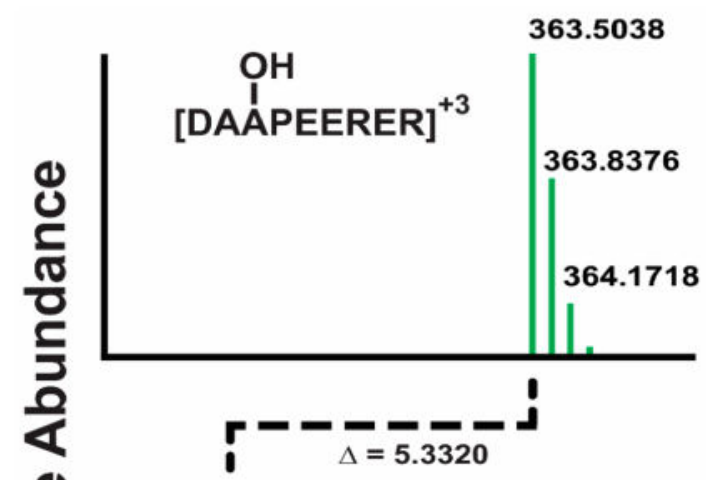

$\$ 358.1718$

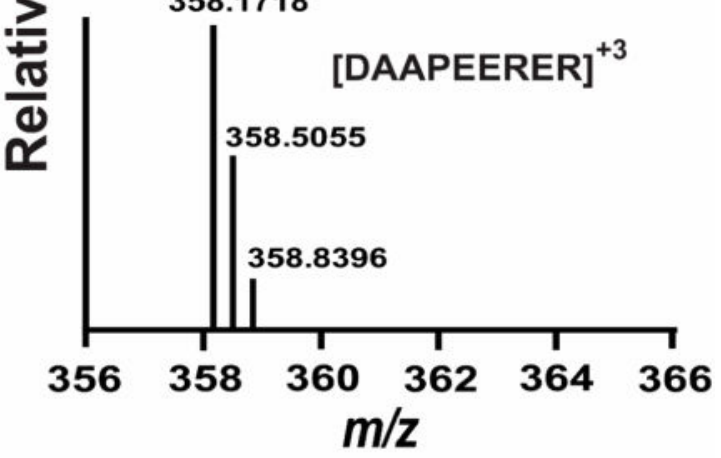

Figure 2.

BaP4H binds and hydroxylates the BaEFTu-9-mer synthetic peptide. (A) The binding affinity of $\mathrm{Fe}(\mathrm{II})-\mathrm{BaP} 4 \mathrm{H}$ with BaEFTu-9 was obtained by monitoring the intrinsic tryptophan fluorescence as the peptide was titrated into an anaerobic solution containing $0.25 \mu \mathrm{M}$ apo-BaP4H, $5 \mu \mathrm{M} \mathrm{Fe}\left(\mathrm{NH}_{4}\right)_{2}\left(\mathrm{SO}_{4}\right)_{2}$, and $100 \mu \mathrm{M} a \mathrm{KG}$. The $K_{\mathrm{d}}$ was determined to be $77 \pm 3 \mathrm{nM}$. (B) XIC peak profiles of [(BaEFTu-9)+OH $]^{3+}$ (green) and (BaEFTu-9) $)^{3+}$ (gray) as separated on a $\mathrm{C}_{18}$ column. (C) MS1 analysis of BaEFTu-9 before and after hydroxylation. The top panel shows $[\mathrm{BaEFTu}-9+\mathrm{OH}]^{3+}$, and the isotopic mass envelope starts at $m / z$ 363.5038. The bottom panel shows the peptide substrate BaEFTu-9, with an isotopic mass envelope starting at $\mathrm{m} / \mathrm{z} 358.1718$. 


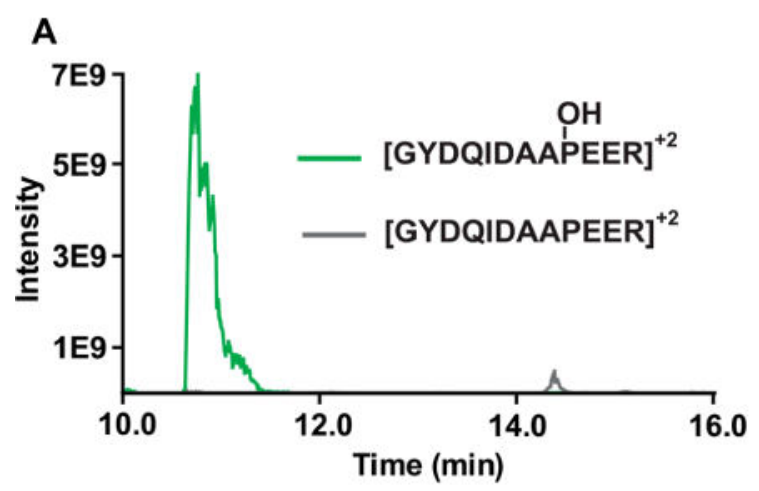

C
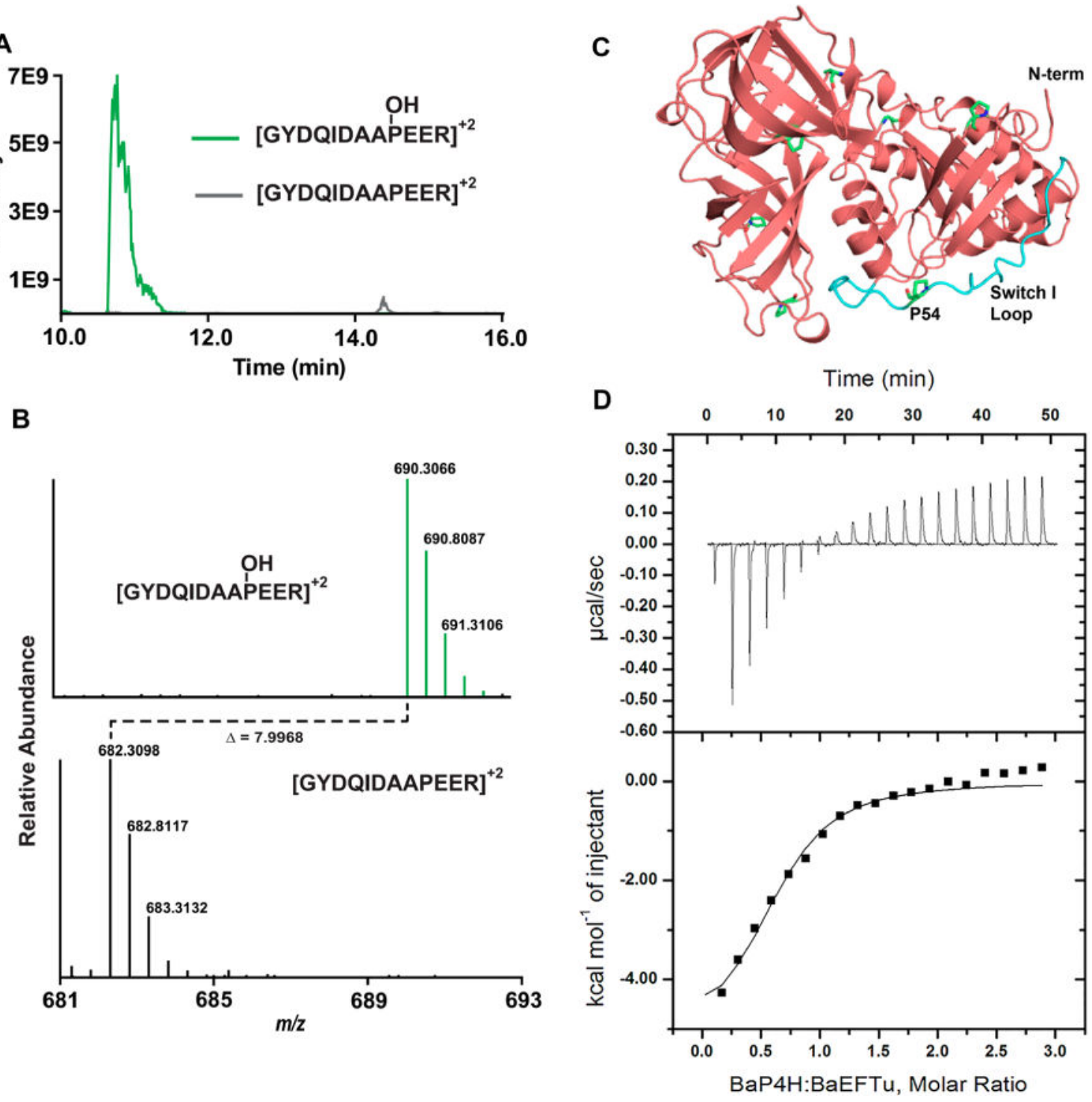

Figure 3.

Identification of site-specific hydroxylated peptide by LC-MS/MS using full-length BaEFTu. (A) XIC peak profile of +2 charged ions of hydroxylated (green) and residual unhydroxylated (gray) peptides as separated on a $\mathrm{C}_{18}$ column. (B) $\mathrm{MS}^{1}$ results for fulllength BaEFTu. The top panel shows a doubly charged ion that contains a hydroxylated Pro 54 residue with a mass of 690.3066 . The bottom panel shows the unhydroxylated peptide ion with a mass of 682.3098 . The mass difference is 7.9968 for the doubly charged ion, which corresponds to the incorporation of a single oxygen atom. (C) A homology model structure of BaEFTu on the basis of the crystal structure of $P$. putida EFTu (PDB entry 4JOQ) shows Pro 54 (green sticks, with oxygens colored red and nitrogens blue) is surface-exposed and within or near the switch I loop region (cyan cartoon). Six other proline residues that were hydroxylated are also shown as green sticks. The homology model was generated using ITASSER $^{49}$ (D) ITC data for a representative titration of $1.12 \mathrm{mM} \mathrm{BaP} 4 \mathrm{H}$ in a syringe and immersed in a cell containing $80 \mu \mathrm{M}$ BaEFTu. The top panel shows the raw measured heat 
changes vs time. The area under each spike is proportional to the heat produced with each injection. The bottom panel shows the integrated areas normalized to the number of moles of $\mathrm{BaP} 4 \mathrm{H}$ injected at each injection step. The data were fitted to a single-binding site model, and the resulting thermodynamic parameters for complex formation are as follows: $\Delta H=$ $-5.5 \pm 0.4 \mathrm{kcal} / \mathrm{mol}, \Delta S=2.63 \mathrm{cal} \mathrm{mol}^{-1} \mathrm{~K}^{-1}, T \Delta S=0.732 \mathrm{kcal} / \mathrm{mol}, \Delta G=-4.77 \mathrm{kcal} / \mathrm{mol}$, and $K_{\mathrm{d}}=13 \pm 2 \mu \mathrm{M}$. 

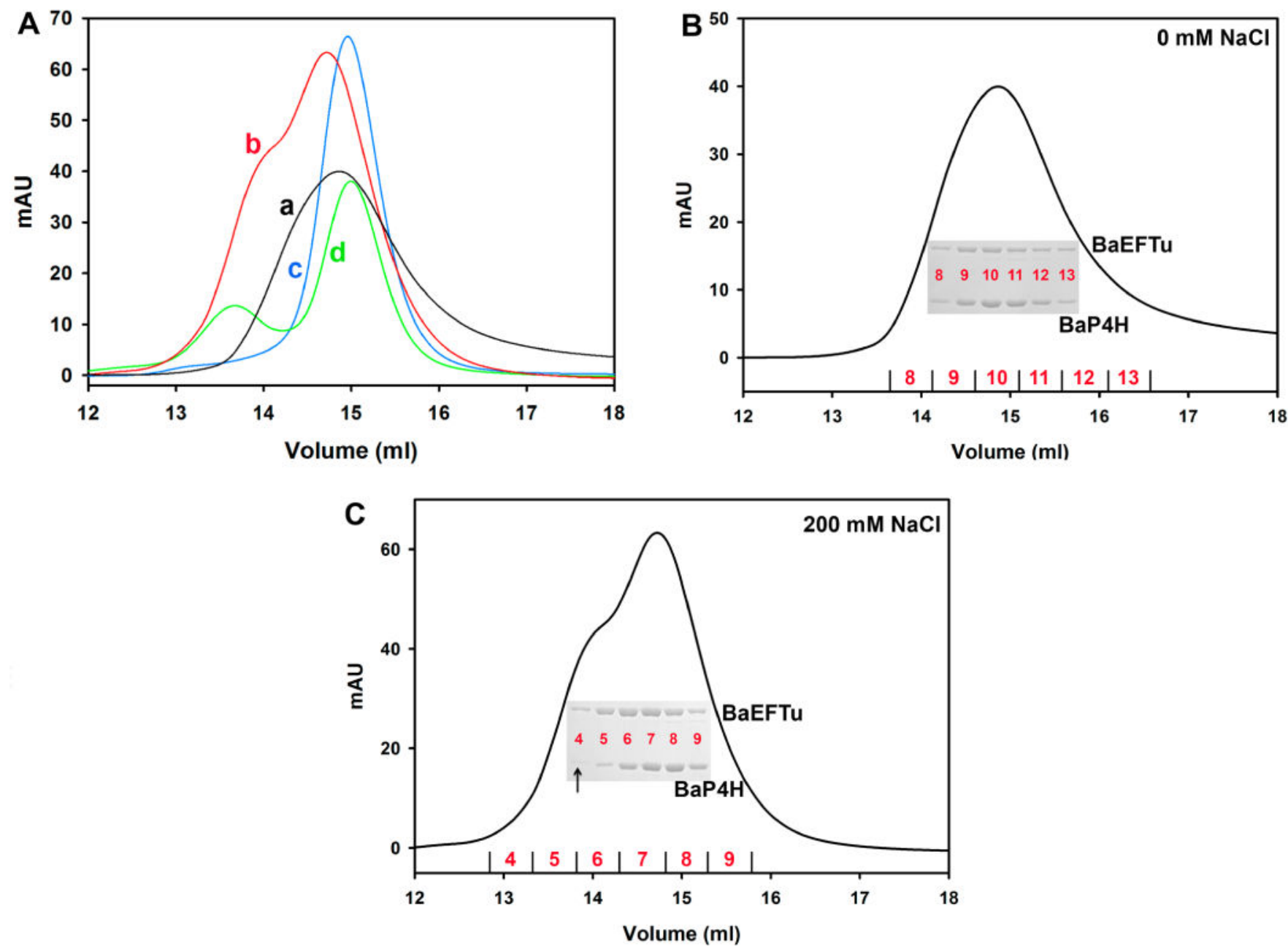

Figure 4.

Gel-filtration chromatography illustrating complex formation between $\mathrm{BaP} 4 \mathrm{H}$ and $\mathrm{BaEFTu}$. An overlay of chromatograms for a 1:1 BaP4H/BaEFTu mixture in the absence (black, a) and presence of $200 \mathrm{mM} \mathrm{NaCl}$ (red, b), free $\mathrm{BaP} 4 \mathrm{H}$ (blue, c), and free $\mathrm{BaEFTu}$ (green, d). (B) The SDS-PAGE gel of eluted fractions (trace a in panel A) was overlaid on the chromatogram and shows approximately equal amounts of BaP4H (MW $\sim 24 \mathrm{kDa}$ ) and BaEFTu (MW $\sim 45 \mathrm{kDa}$ ) across the peak. (C) The SDS-PAGE gel of eluted fractions (trace $\mathrm{b}$ in panel A) was overlaid on the chromatogram, showing the higher-MW BaEFTu that elutes at $14 \mathrm{~mL}$ matches well with the shoulder observed in the elution profile (trace $\mathrm{b}$ in panel A) and the BaEFTu dimer peak (trace d in panel A). The arrow in the first lane of the gel indicates a lack of $\mathrm{BaP} 4 \mathrm{H}$. In both panels $\mathrm{B}$ and $\mathrm{C}$, fraction numbers are marked on the elution profiles and correlated to lane numbers in the gels. 

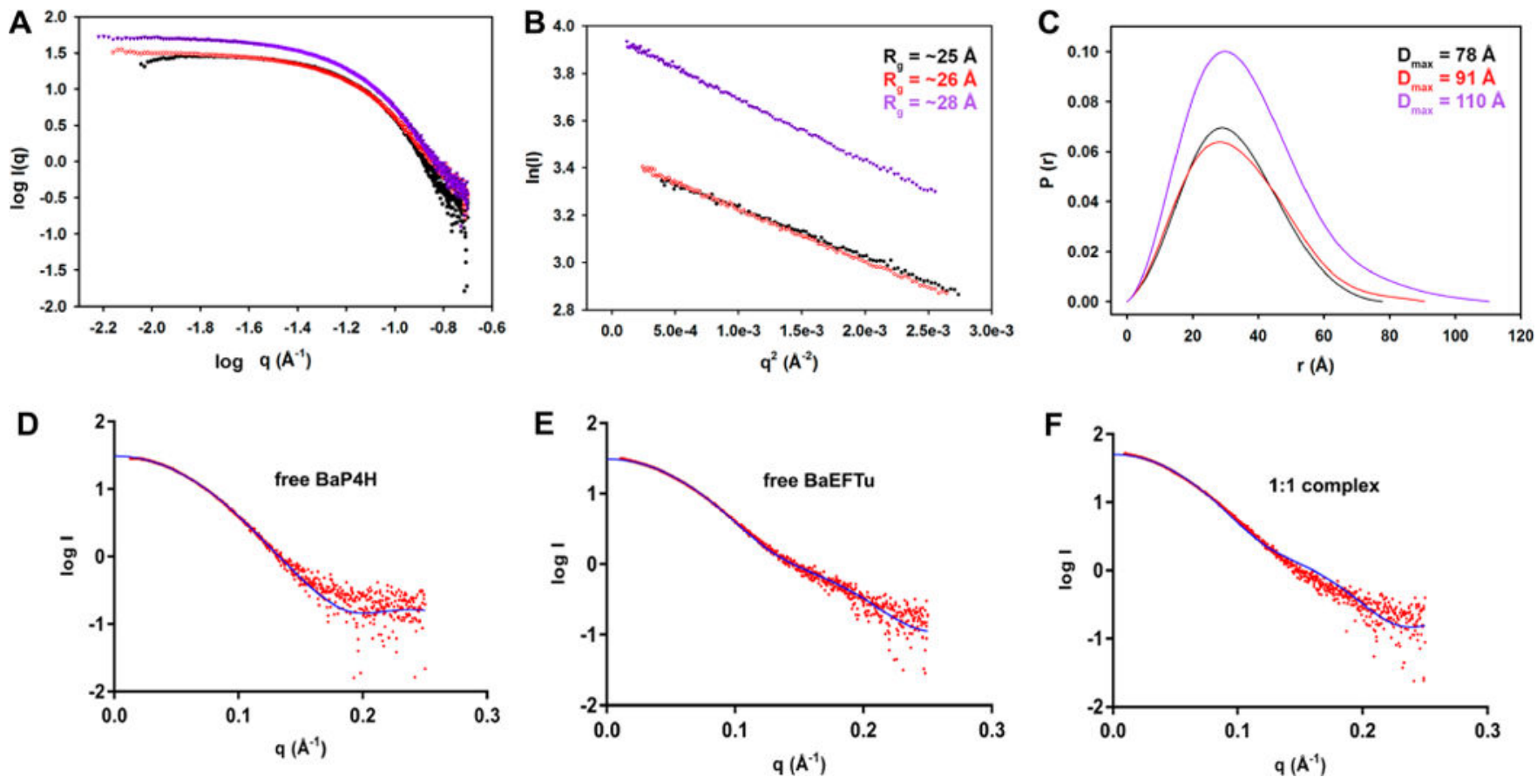

Figure 5.

SAXS data of the BaP4H-BaEFTu complex (purple), free BaP4H (black), and free BaEFTu (red). (A) Scattering profiles of the individual proteins and the BaP4H-BaEFTu complex.

Each curve represents an average of five different curves collected around the peak from the gel-filtration chromatogram. (B) Guinier plot of $\mathrm{BaP} 4 \mathrm{H}$ and $\mathrm{BaEFTu}$ alone and mixed together, showing linearity in the low $q$ range and slight differences in the slope corresponding to the difference in the radii of gyration $\left(R_{\mathrm{g}}\right)$. The Guinier equation $[\ln I(q)=$ $\left.\ln I(0)-R_{g}{ }^{2} q_{g}^{2} / 3\right]$ was used for data analysis. (C) Pair-distance distribution $[P(r)]$ plots of free proteins and the $\mathrm{BaP} 4 \mathrm{H}-\mathrm{BaEFTu}$ complex, with maximum dimensions $\left(D_{\max }\right)$ for individual proteins that do not exceed $91 \AA$. The $D_{\max }$ for the mixture of the two proteins extends to $110 \AA$ A. (D-F) Comparison of theoretical scattering curves (blue), calculated using CRYSOL, with the experimental scattering profiles (red) for the free $\mathrm{BaP} 4 \mathrm{H}$ dimer, free BaEFTu, and the 1:1 BaP4H-BaEFTu complex, respectively. 


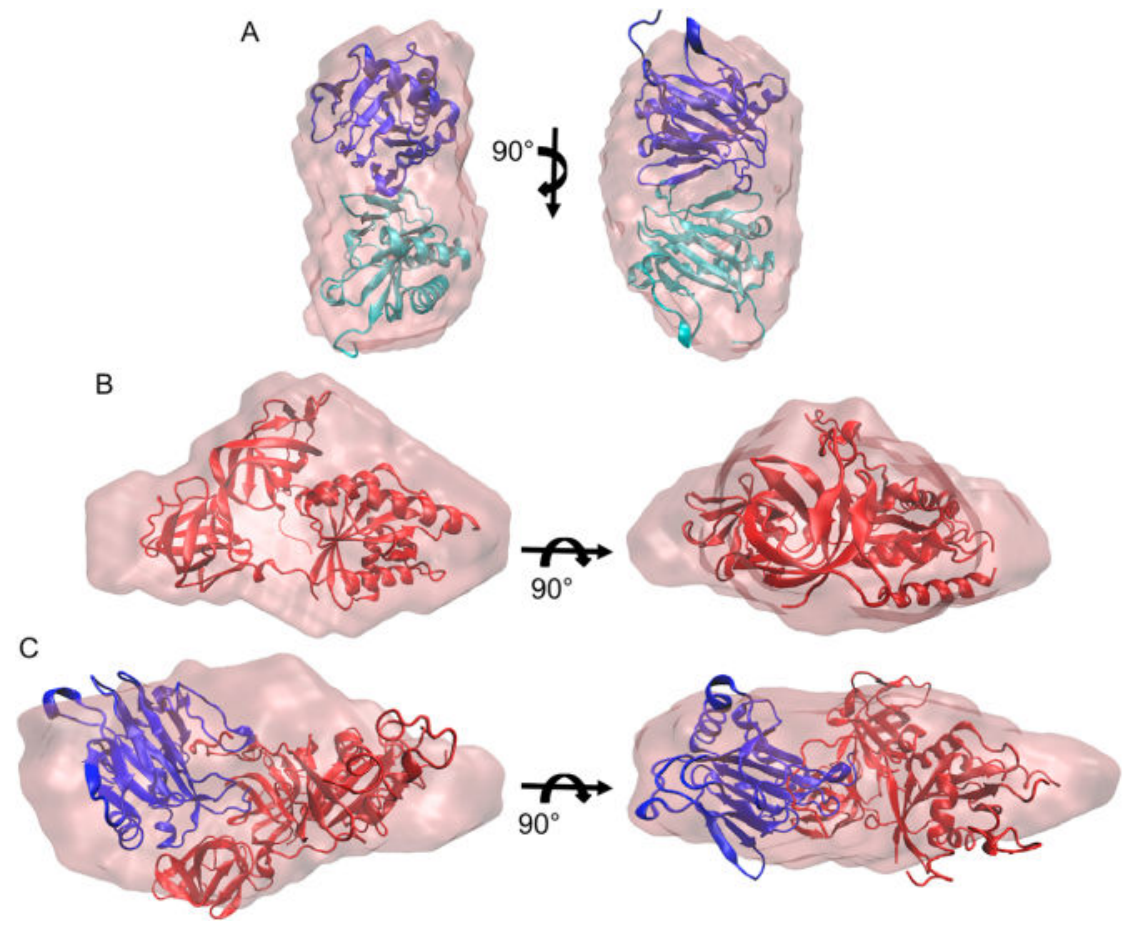

Figure 6.

SAXS-derived ab initio shape reconstructions depicting solution conformations of free $\mathrm{BaP} 4 \mathrm{H}$, free BaEFTu, and a complex of the two, with two different views. (A) The envelope generated from the shape reconstruction of SAXS data from BaP4H fits well with the crystal structure (PDB entry 5V7Y) of the dimer (blue and green cartoon). (B) The envelope of BaEFTu aligns well with a homology model structure (red cartoon) generated on the basis of the crystal structure of $P$. putida EFTu (PDB entry 4JOQ). (C) The molecular envelope reconstructed from an equimolar solution of the $\mathrm{BaP} 4 \mathrm{H}$ dimer and a BaEFTu monomerdimer mixture is aligned with the crystal structure of the PPHD-EFTu complex (PDB entry 4IW3) and matches well with a 1:1 complex (cartoons, same coloring as in panels A and B). The depicted rotation in panel $\mathrm{A}$ is about the vertical axis, and the rotation in panels $\mathrm{B}$ and $\mathrm{C}$ are about horizontal axes. 
A

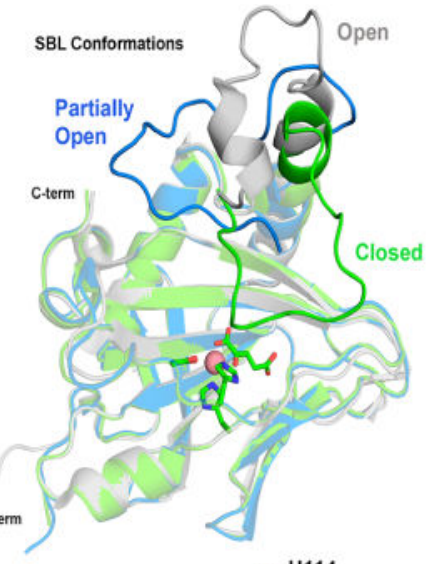

B
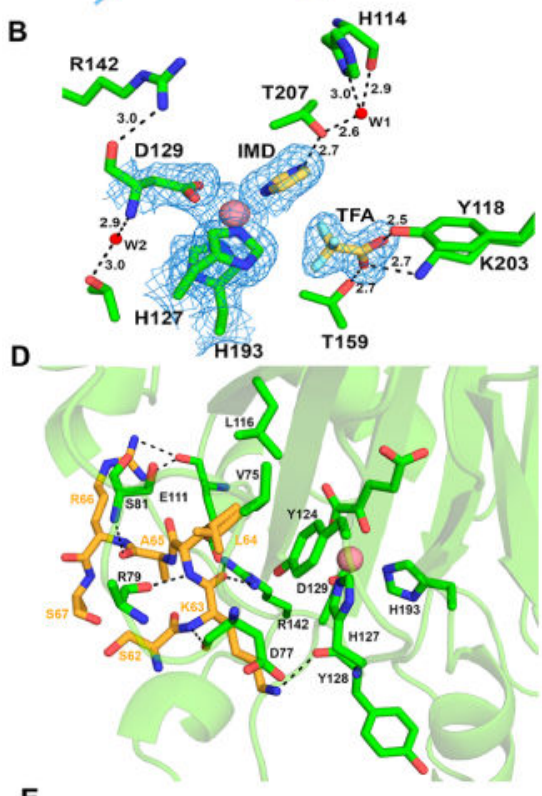

E

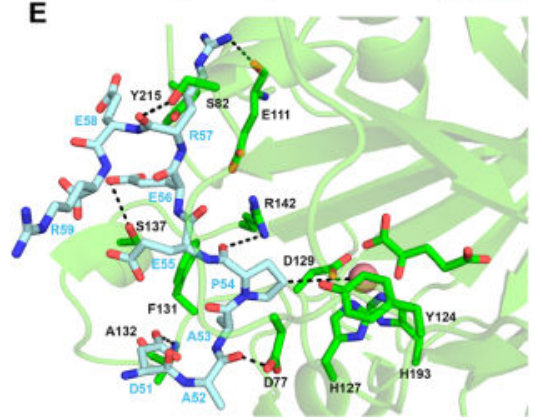

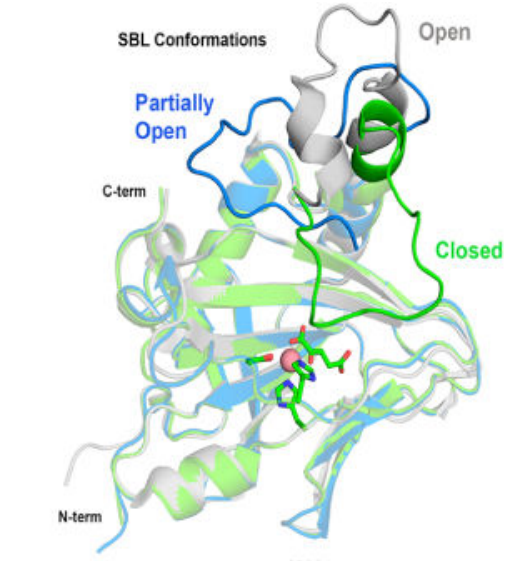

C
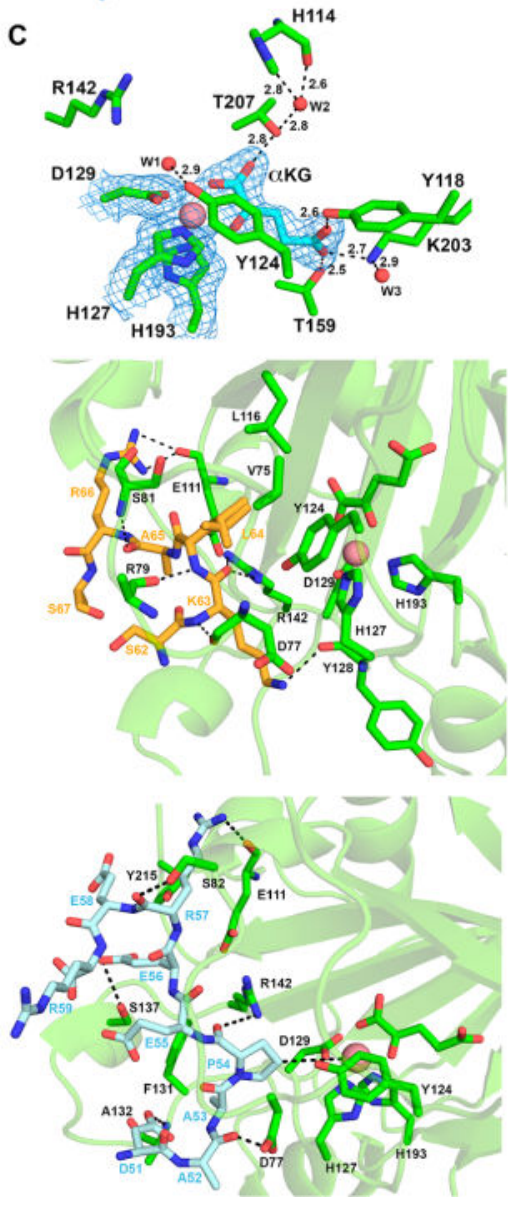

Figure 7.

$\mathrm{Co}(\mathrm{II})-\mathrm{BaP} 4 \mathrm{H}$ structure highlighting the substrate binding loop (SBL) and modeled peptide. (A) Cross-eyed stereoview of the structural alignment of $\mathrm{Co}$ (II)-BaP4H chain $\mathrm{B}$ (green), $\mathrm{Co}$ (II)-BaP4H chain A (blue), and apo-BaP4H chain A (gray, PDB entry 5IAT) displaying differences in the SBL region (residues 62-82). (B) Active site residues of $\mathrm{Co}$ (II)-BaP4H chain A showing hydrogen bonding interactions among the protein, TFA, imidazole, and water with labeled distances. These interactions are similar in chains $\mathrm{C}$ and D. (C) Active site of $\mathrm{Co}(\mathrm{II})-\mathrm{BaP} 4 \mathrm{H}$ chain $\mathrm{B}$ with bound $a \mathrm{KG}$ showing hydrogen bonds among the protein, 
$a \mathrm{KG}$, and water with corresponding distances. In both panels B and $\mathrm{C}$, the $F_{\mathrm{O}}-F_{\mathrm{c}}$ omit map (shown as blue mesh) for Co, bound ligands, TFA, imidazole, and $a \mathrm{KG}$ is contoured at $3.0 \sigma$. (D) Cross-eyed stereoview of interactions between residues 62-67 of SBL from chain A of a symmetry molecule (orange sticks) and the active site of chain B (green sticks). (E) A stereoview of the docked DAAPEERER peptide (residues 51-59 shown as cyan sticks, with oxygens colored red and nitrogens blue) shows possible contacts in the $\mathrm{BaP} 4 \mathrm{H}$ active site. Position C-4 of Pro 54 in BaEFTu-9 is in an endo conformation and is $5 \AA$ from the metal center. (A-E) Metal binding residues (His 127, Asp 129, and His 193), aKG, all ligands, and residues are shown as sticks: carbon (protein backbone color), oxygen (red), and nitrogen (blue). The cobalt atom is shown as a pink sphere, and water molecules are shown as red spheres. Various interactions are indicated by black dashes. 


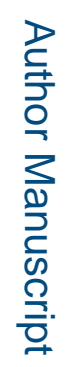

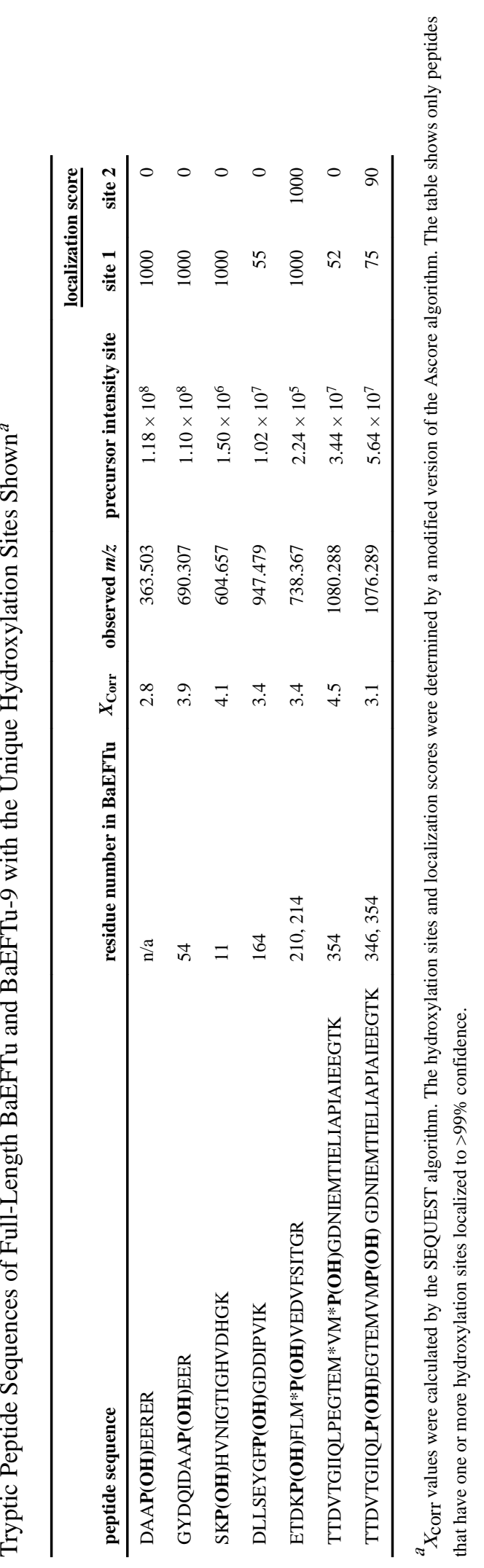

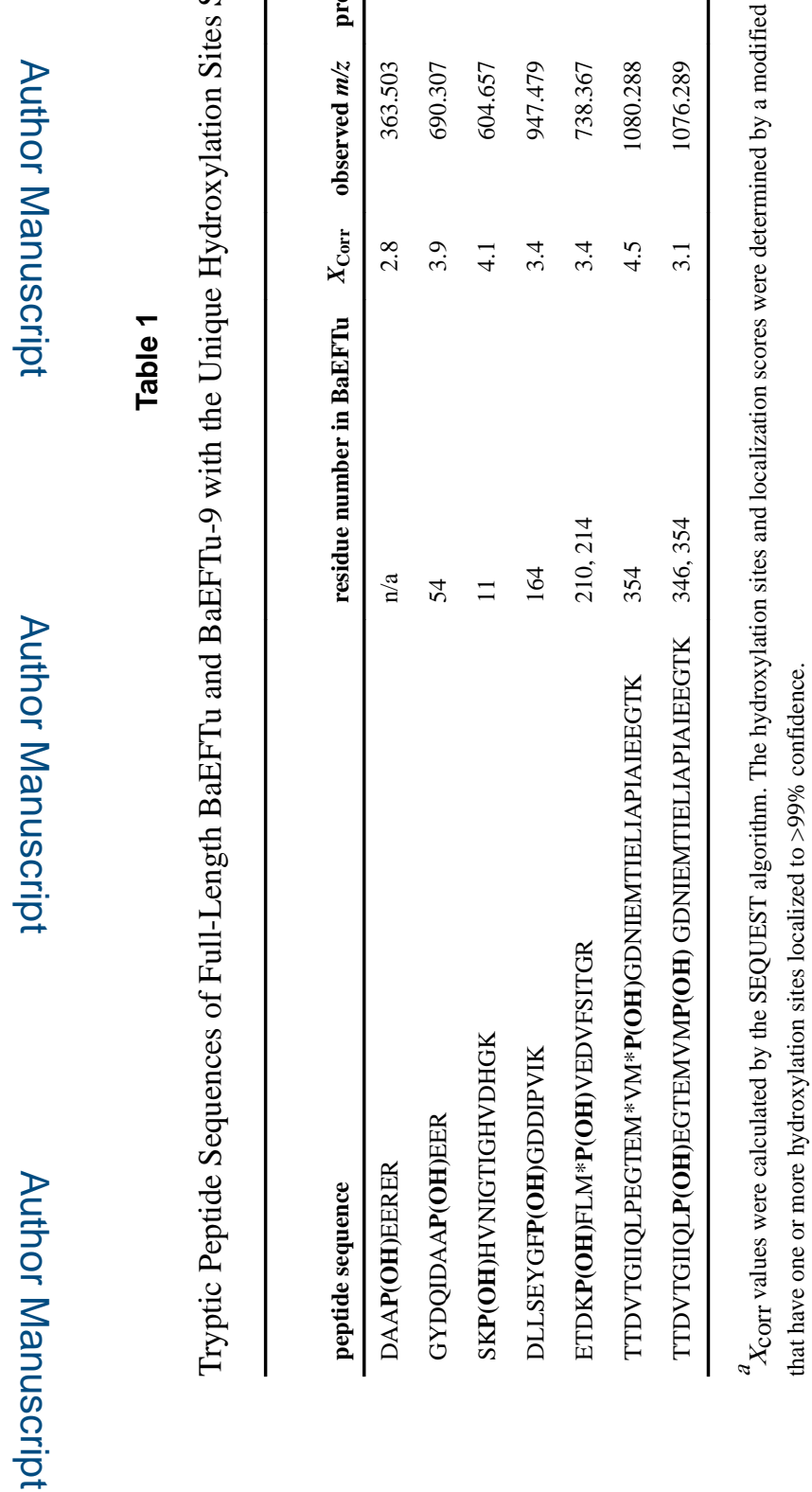

Biochemistry. Author manuscript; available in PMC 2017 December 19. 
Table 2

Data Collection and Refinement Statistics for Co(II)-BaP4H

\begin{tabular}{|c|c|}
\hline & \\
\hline space group & $P 12_{1} 1$ \\
\hline \multicolumn{2}{|l|}{ unit cell dimensions } \\
\hline$a, b, c(\AA)$ & $50.2,106.8,81.1$ \\
\hline$a, \beta, \gamma(\mathrm{deg})$ & $90,103.7,90$ \\
\hline beamline & ALS 4.2.2 \\
\hline wavelength $(\AA)$ & 1.00 \\
\hline PDB entry & $5 \mathrm{~V} 7 \mathrm{Y}$ \\
\hline resolution range $(\AA)^{a}$ & $63.4-2.05(2.11-2.05)$ \\
\hline no. of observations ${ }^{a}$ & $187624(14618)$ \\
\hline no. of unique reflections ${ }^{a}$ & 51889 (4087) \\
\hline redundancy ${ }^{a}$ & $3.6(3.6)$ \\
\hline completeness $(\%)^{a}$ & $99.5(99.9)$ \\
\hline$I / \sigma(I)^{a}$ & $13.3(2.7)$ \\
\hline$R_{\text {merge }}(\%)^{a, b}$ & $7.3(40.4)$ \\
\hline$R_{\mathrm{pim}}(\%)^{\mathrm{a}, c}$ & $6.9(36.7)$ \\
\hline \multirow[t]{2}{*}{$\mathrm{CC}_{1 / 2}$} & $0.996(0.813)$ \\
\hline & \\
\hline$R_{\text {work }}, R_{\text {free }} d_{(\%)}$ & $16.1,20.9$ \\
\hline resolution range $(\AA)$ & $63.4-2.05$ \\
\hline no. of reflections & 51781 \\
\hline \multicolumn{2}{|l|}{ no. of atoms } \\
\hline protein & 6445 \\
\hline Co & 4 \\
\hline$a \mathrm{KG}$ & 10 \\
\hline TFA & 21 \\
\hline IMD & 25 \\
\hline water & 604 \\
\hline \multicolumn{2}{|l|}{ average $B$ factor $\left(\AA^{2}\right)$} \\
\hline protein & 21.9 \\
\hline Co & 14.3 \\
\hline$a \mathrm{KG}$ & 21.2 \\
\hline TFA & 27.6 \\
\hline IMD & 23.6 \\
\hline water & 30.1 \\
\hline root-mean-square deviation for bond lengths ( $\AA$ ) & 0.012 \\
\hline root-mean-square deviation for bond angles (deg) & 0.9 \\
\hline Ramachandran favored (\%) & 97.7 \\
\hline
\end{tabular}

Biochemistry. Author manuscript; available in PMC 2017 December 19. 


\begin{tabular}{ll} 
& Data Collection \\
& \\
Ramachandran allowed (\%) & 2.3 \\
Clash score & 2.7 \\
\hline
\end{tabular}

${ }^{a}$ Values in parentheses are for the highest-resolution shell.

${ }^{b} R_{\text {merge }}=\Sigma_{h k} \sum_{i}\left|I_{I}(h k l)-\langle I(h k I)\rangle\right| \Sigma_{h k} \sum_{i} I_{I}(h k l)$, where $I_{I}(h k l)$ is the th measured diffraction intensity and $\langle I(h k l)\rangle$ is the mean intensity for the Miller index $(h k l)$.

$c R_{\text {pim }}=\sum_{h k l}\left[\frac{1}{n(h k l)-1}\right]^{1 / 2} \sum_{i}\left|I_{i}(h k l)-\langle I(h k l)\rangle\right| / \sum_{h k l} \sum_{i} I_{i}(h k l)$.

$d_{R_{\text {free }}}=R_{\text {factor }}$ for a test set of reflections $(5 \%)$. 


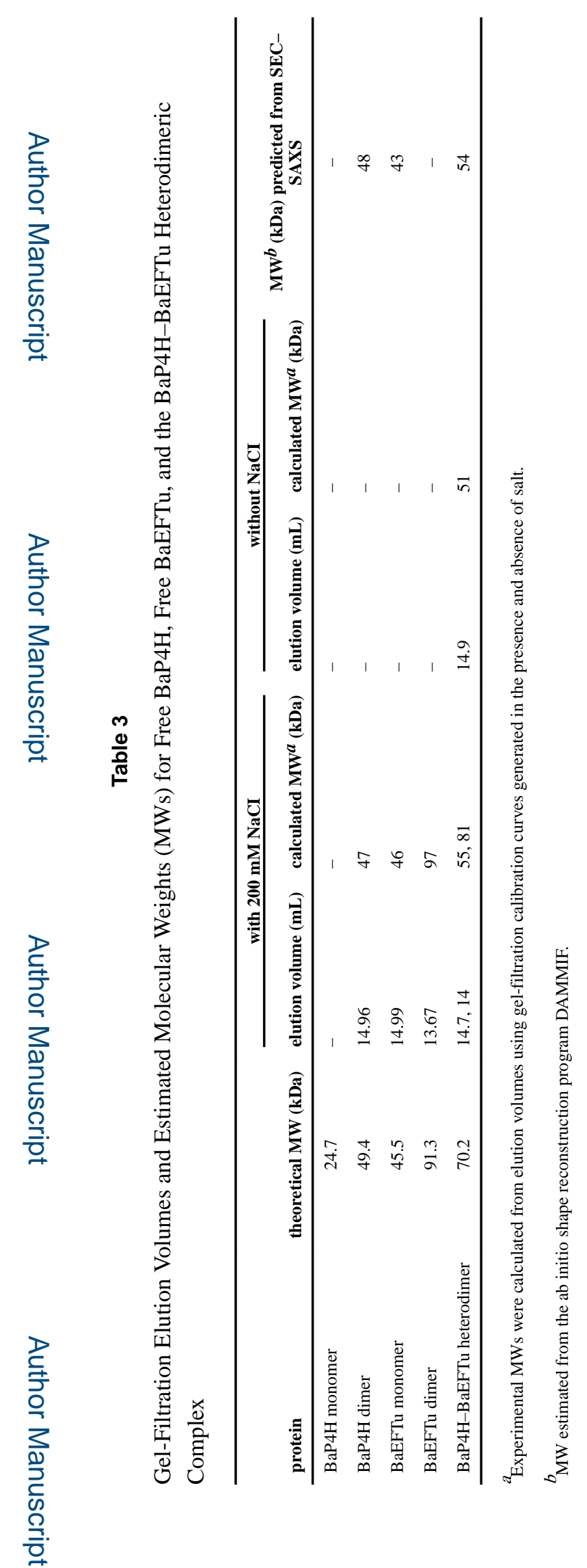

Biochemistry. Author manuscript; available in PMC 2017 December 19. 